\title{
DAMAGE ANALYSIS OF BRIDGES AFFECTED BY THE TSUNAMI IN THE GREAT EAST JAPAN EARTHQUAKE
}

\author{
Kenji KOSA ${ }^{1}$ \\ ${ }^{1}$ Member of JSCE, Professor, Dept. of Civil Eng., Kyushu Institute of Technology \\ (Sensui 1-1, Tobata-ku, Kitakyushu 804-8550, Japan) \\ E-mail: kosa@civil.kyutech.ac.jp
}

\begin{abstract}
The tsunami caused by the Great East Japan Earthquake hit the coast of Eastern Japan. The outflow conditions of 37 bridges were evaluated using $\beta$ (the ratio of resistance to the tsunami force). $\beta$ was found effective in judging the girder outflow. Moreover, two analytical approaches (video and numerical analyses) were conducted to evaluate the tsunami characteristics and outflow mechanisms of girders. In Shizugawa town, based on video analysis, the tsunami height and velocity variations were estimated. Besides, two mechanisms on the bridge girder at Shizugawa were analyzed (One, as the tsunami hit the girder but did not submerge it; the other, as the tsunami submerged the girder totally). It was noted that in both two mechanisms, the girder was strong enough to resist the tsunami. In Utatsu Bridge, by video and numerical analyses, the wave height was observed to rise slowly, which indicated that the wave shape was not a bore wave. Moreover, it was found that when the girders of Utatsu Bridge were flooded, due to effect of buoyancy, the resistance of the girders was insufficient to resist the tsunami force.
\end{abstract}

Key Words : tsunami, outflow of bridge, $\beta$ ratio, video analysis, numerical analysis

\section{INTRODUCTION}

The 2011 Tohoku Earthquake, also known as the 2011 Great East Japan Earthquake, was a magnitude 9.0 undersea earthquake that occurred at 14:46 (JST) on $11^{\text {th }}$ March 2011, with its epicenter about $130 \mathrm{~km}$ southeast to Oshika Peninsula. Due to the great tsunami triggered by the earthquake, East Japan suffered tremendous destructions. According to the report of Japan Meteorological Agency, wave heights from $7 \mathrm{~m}$ to $12 \mathrm{~m}$ were observed from the northern area of Fukushima Prefecture to the southern area of Iwate Prefecture.

Soon after the great earthquake, the author conducted field investigations in the disaster areas of Japan. As shown in Fig.1, 24 bridges (made of 37 types of girders) located near the coastline are the subjects of this study. First, the girder outflow will be evaluated using the $\beta$ value (ratio of girder resistance to the tsunami lateral force). Second, the drag coefficient, which is one of the parameters deciding the tsunami force, will be discussed.

Although the $\beta$ ratio can be confirmed effective to evaluate bridge outflow, but the detailed outflow mechanism corresponding to outflow condition is

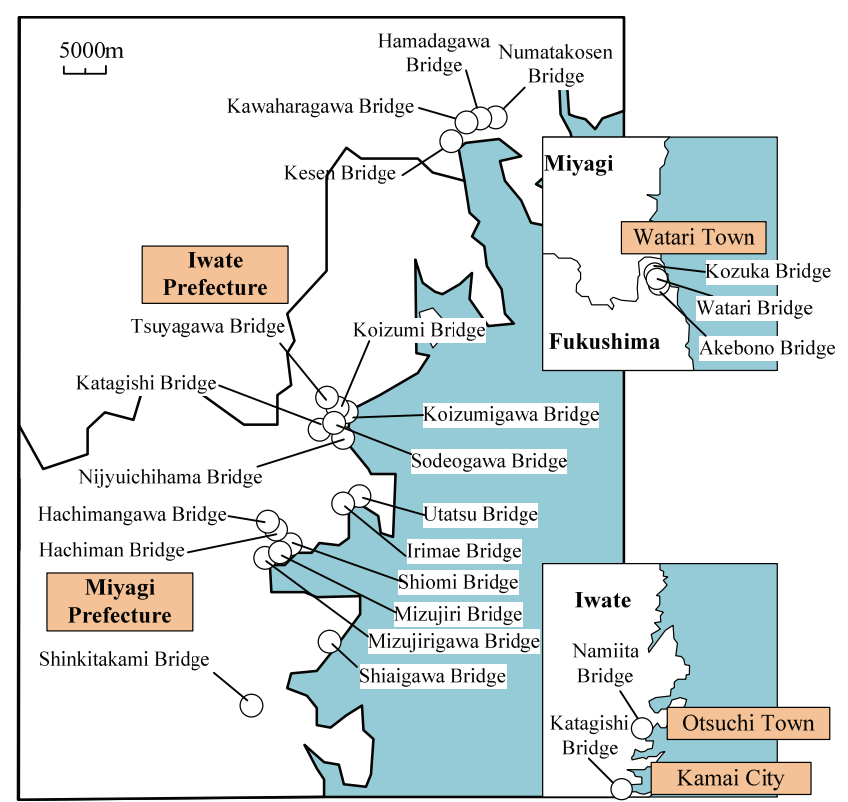

Fig.1 General Tohoku area.

still unclear. So the video and numerical analyses were used to evaluate the tsunami characteristics of two representative areas in order to get the mechanism of girder outflow. First one, the Shizugawa 
town is selected as an example, the tsunami height and velocity time histories were estimated using the video recordings of the tsunami progress. Based on the tsunami characteristics, two different mechanisms (One, as the tsunami hit the girder but did not flood it; the other, as the tsunami submerged the girder totally) were summarized and the evaluation of girder outflow is conducted. As the second, the Utatsu Bridge, located at the coast of Minamisanriku town in Miyagi prefecture, was selected. From the survey, it was observed that eight girders were washed away by the tsunami. For these girders, the wave height and velocity time histories were plotted using the video and two dimensional numerical analysis. Afterwards, the outflow of girders were also evaluated.

\section{EVALUATION OF BRIDGE OUTFLOW BY $\beta$ RATIO}

In this chapter, the author first estimated the tsunami force on the girder and the girder resistance. After that, the $\beta$, which is the ratio of the girder lateral resistance to the tsunami lateral force, was computed to investigate whether a relationship existed between $\beta$ and the girder outflow condition. It is found that if defining the girder outflow ranks as listed in Table 1, the results showed that the levels of $\beta$ for Ranks $\mathrm{A}$ and $\mathrm{C}$ were quite different. The reasons why the $\beta$ of some bridges did not coincide with their damaged conditions were then discussed.

The tsunami can be calculated by Eq. (1), while girder resistance can be computed by Eq. (2) or Eq. (3). When the bridge girder is simply hit by the tsunami but is not submerged by waves, Eq. (2) is used. When the bridge girder is submerged totally by waves, Eq. (3) is applied and buoyancy should be considered. Eq. (2) and Eq. (3) are discussed as follows:

$$
F=\frac{1}{2} \rho_{w} C_{d} v^{2} A_{h}
$$

$$
\begin{gathered}
S=\mu W \\
S=\mu(W-U)
\end{gathered}
$$

Where $\rho_{w}$ is density of water $\left(1030 \mathrm{~kg} / \mathrm{m}^{3}\right)$; $C_{d}$ is drag coefficient with its value decided based on reference $^{1)} ; v$ is tsunami velocity; $A_{h}$ is the projected area of girder in horizontal direction; $\mu$ is friction coefficient $\left(0.6\right.$, based on research $\left.{ }^{2}\right)$; $W$ is dead load of girder. $U$ is buoyancy which is computed by Eq. (4):

$$
U=\rho_{w} g V
$$

Where $V$ is volume of the bridge girder submerged by the tsunami.

Thus, the $\beta$ ratio is got from Eq. (5):

$$
\beta=\frac{S}{F}
$$

Table 1 Defiition of damage ranks.

\begin{tabular}{|c|c|}
\hline $\begin{array}{c}\text { Damage } \\
\text { level }\end{array}$ & Outflow condition of superstructure \\
\hline Rank A & Flowed out compeletly \\
\hline Rank B & Moved but not divorced from abutment \\
\hline Rank C & Slight damage \\
\hline
\end{tabular}

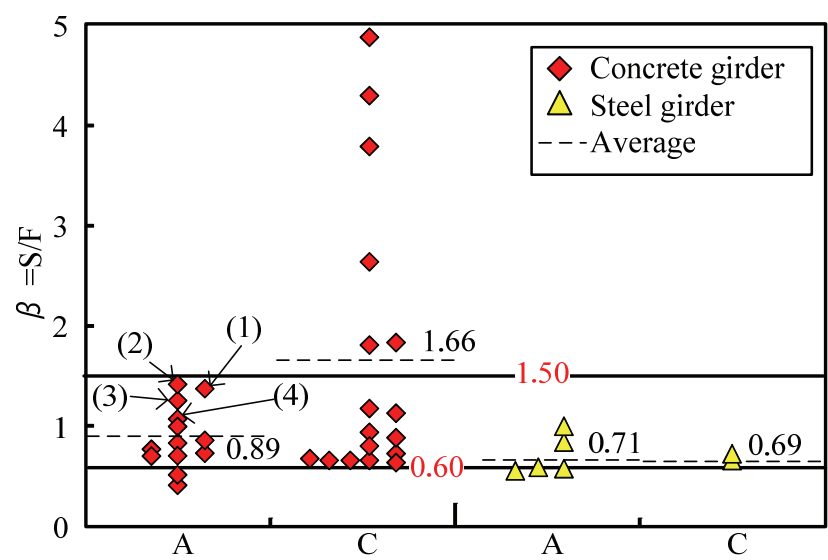

Fig.2 $\beta$ ratios for entire Tohoku.

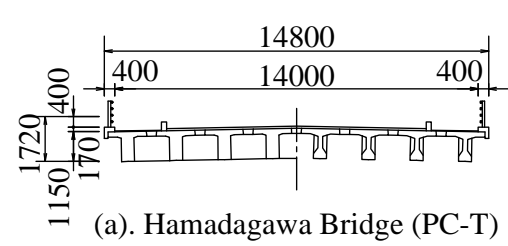

(a). Hamadagawa Bridge (PC-T)

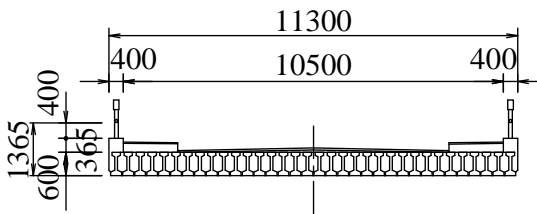

(b). Shiomi Bridge (PC-I)

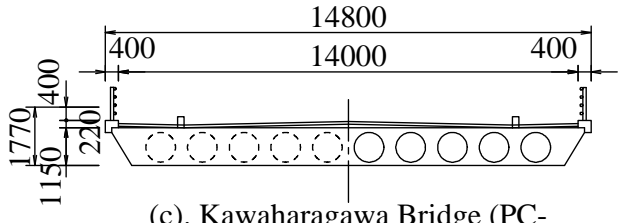

(c). Kawaharagawa Bridge (PChollow)

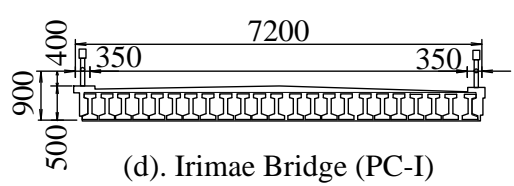

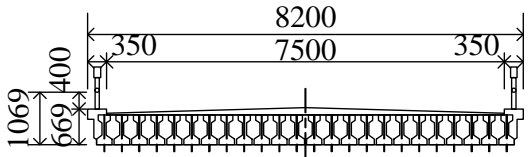

(e). Hachiman Bridge (PC-I)

Fig.3 Section views of bridges with $\beta$ ratios greater than 2.0. 
If $\beta$ is smaller (greater) than 1.0 , it indicates that the girder resistance is smaller (greater) than the tsunami force, which means the girder is easy (difficult) to be swept out. For the tsunami velocity $(v)$ in Eq. (1), based on many recorded videos in the East Japan, the ave. value $6.0 \mathrm{~m} / \mathrm{s}^{3)}$ is applied.

Fig.2 illustrates the computed $\beta$ for 37 girders. When $\beta$ is larger than 1.5 , the girders suffer the damage of Rank $\mathrm{C}$ but when $\beta$ is smaller than 0.6 , the girders suffer the damage of Rank A. Thus, it is concluded that a gap in $\beta$ value exists between Rank A and Rank C, and it is effective to apply $\beta$ to evaluate outflow of girder.

To check the characteristics of easily outflowed and difficultly outflowed bridges, the section views of difficultly outflowed girders with $\beta$ greater than 2.0 are shown in Fig.3, the section views of easily outflowed girders with $\beta$ smaller than 0.6 are illustrated in Fig.4. The girders of difficultly outflowed bridges were all found to belong to the PC (prestressed conrete) type. Three of four girders were made of PC-I. Further, the difficultly outflowed girders were discovered to be relatively in flat shape.
As to the difficultly outflowed bridges, overall girder height was in smaller level and girder width was in greater level compared with those for the easily outflowed bridges.

If the bridge height is small, the tsunami impact area per unit girder length tends to be small. If the bridge width is greater, the girder weight per unit length tends to be great. Thus, greater $\beta$ occurred. As a result, the author considers that great bridge width and small bridge height will cause the bridges to have great $\beta$ and lead to great resistant ability.

In previous research ${ }^{4), 5)}$, obvious $\beta$ level differences were found for Rank A and Rank C. But in Fig.2, some $\beta$ of Rank A concrete girders are larger

Table 2 Rank A concrete bridges with $\beta$ greater than 1.0.

\begin{tabular}{|c|c|c|c|}
\hline \multicolumn{4}{|c|}{ Rank A concrete bridges with $\beta$ greater than 1.0} \\
\hline No. & Name & $\beta$ & Girder Type \\
\hline$(1)$ & \multirow{3}{*}{ Numatakosen } & 1.37 & PC-T \\
\cline { 3 - 4 } & & 1.41 & PC-T \\
\hline$(2)$ & Shimoya & 1.25 & PC-T \\
\hline$(3)$ & Kozuka & 1.07 & PC-T \\
\hline
\end{tabular}

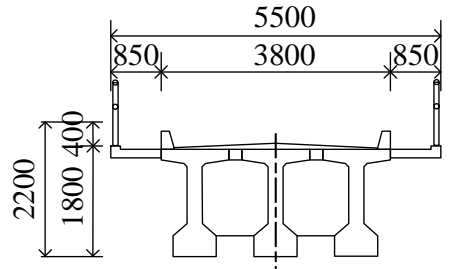

(f). Mizujirigawa Bridge (PC-I)

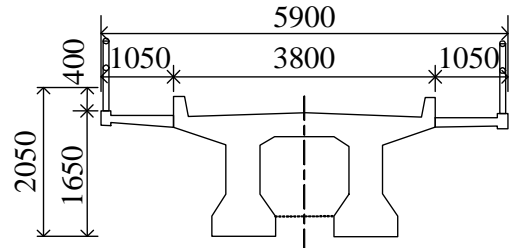

(g). Hachimangawa Bridge (RC-I)

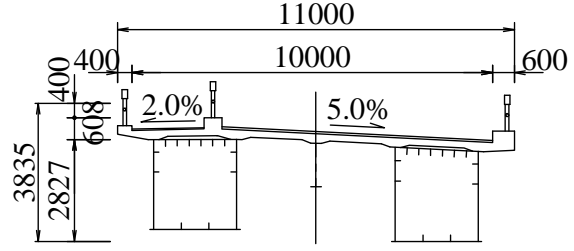

(h). Shiaigawa Bridge (Steel-box)

Fig.4 Section views of bridges with $\beta$ ratios smaller than 0.6.

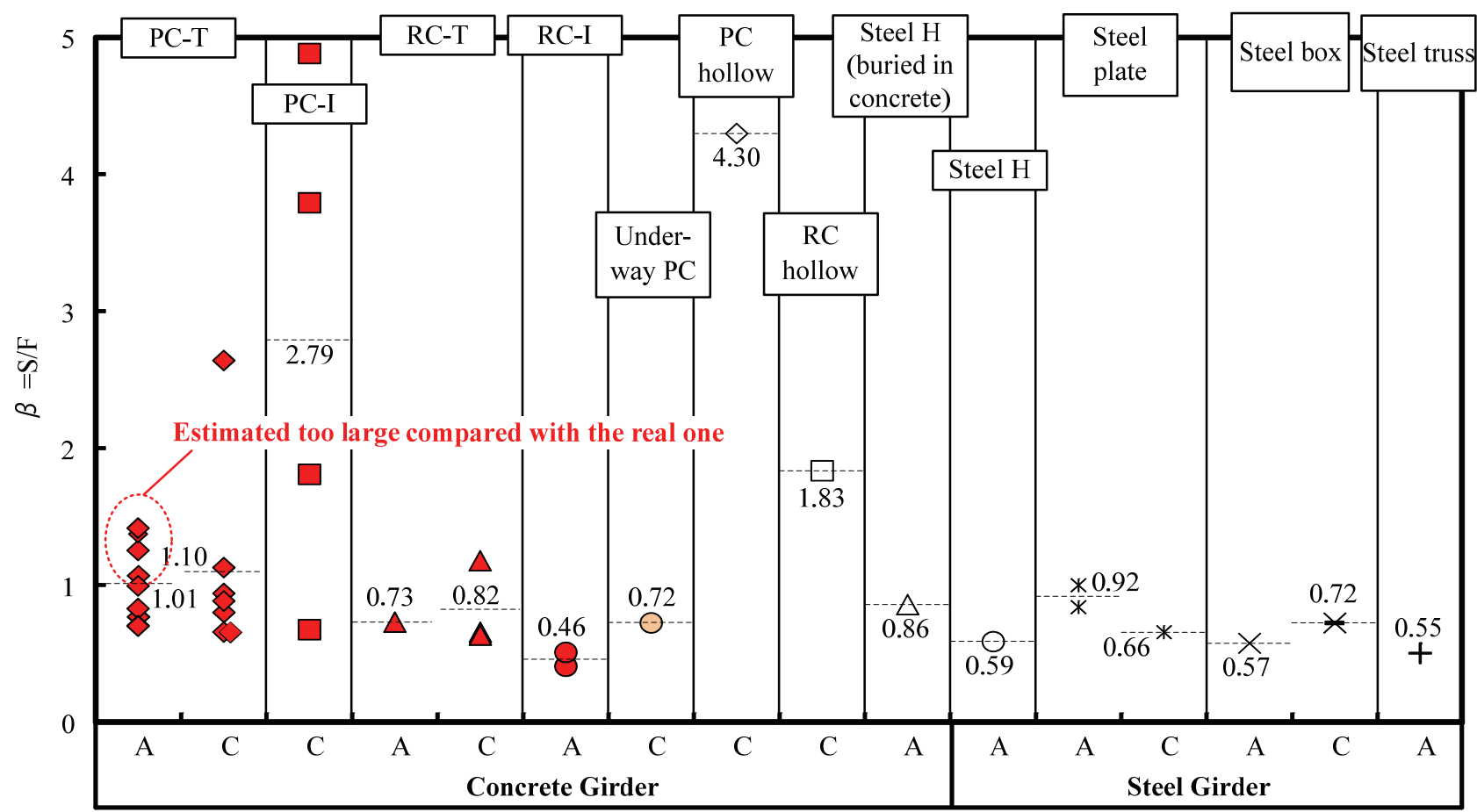

Fig.5 Classification of $\beta$ by different girder types. 


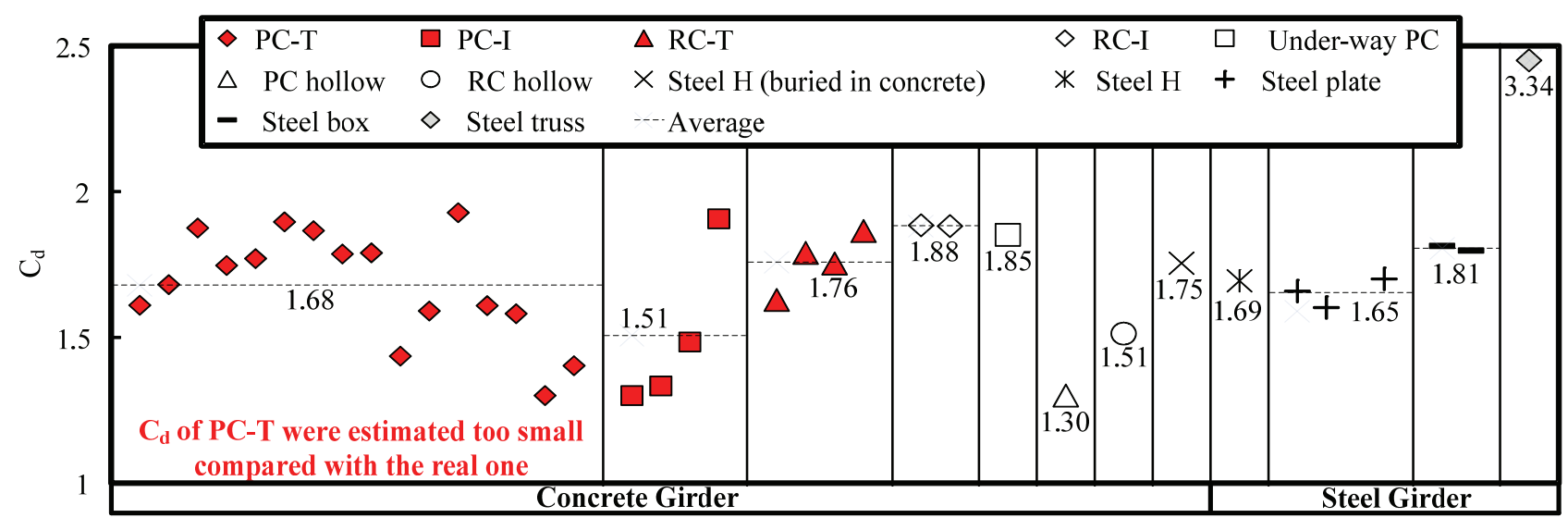

Fig.6 Influence on drag coefficient from different girder types.

than 1.0 and some $\beta$ of Rank $\mathrm{C}$ girders are smaller than 1.0 .

The reason appears to be that first, the author note that the tsunami velocity affects the tsunami force significantly. Here, the velocity $6.0 \mathrm{~m} / \mathrm{s}$ is applied, but in different areas, wave velocities might be different.

Table 2 shows the bridge details, the $\beta$ values of which do not coincide with damage ranks. All Rank A girders with $\beta$ larger than 1.0 are found to belong to PC-T types. Thus, first the $\beta$ are classified by girder type, as shown in Fig.5, to check the $\beta$ ratios of PC-T girders. As a result, the author found that compared with the $\beta$ of other concrete girders of Rank A, the PC-T has great $\beta$ with an average of 1.01. Therefore, the author suppose that the tsunami forces on PC-T girders are estimated to be smaller than the real ones, which leads to the larger $\beta$ than what is real.

Considering the reason why the tsunami forces are evaluated smaller than real, besides the effect of tsunami velocity, associating with Eq. (1), the drag coefficient $C_{d}$ is considered to be estimated as small. When it comes to the previous calculation method of drag coefficient, based on the specification ${ }^{1)}$, it was computed by Eq. (6) and Eq. (7). (Eq. (7) calculates truss-type bridges, while Eq. (6) is for other types):

$$
\begin{aligned}
& C_{d}= \begin{cases}2.1-0.1(B / D) & 1 \leq B / D<8 \\
1.3, & 8 \leq B / D\end{cases} \\
& C_{d}=1.35 / \sqrt{\phi}(0.1 \leq \phi \leq 0.6)
\end{aligned}
$$

Where $C_{d}$ is the drag coefficient; $B$ is the bridge width (m); $D$ is the bridge height (m); $\phi$ is the fill rate as the ratio of the truss area to the external contour area.

In order to plot the characteristics of drag coefficient distribution of PC-T, the drag coefficient distributions are classified based on girder type as well, as shown in Fig.6. From Fig.6, it can be seen that the ave. drag coefficient of PC-T is close to those of other concrete types. However, considering the real

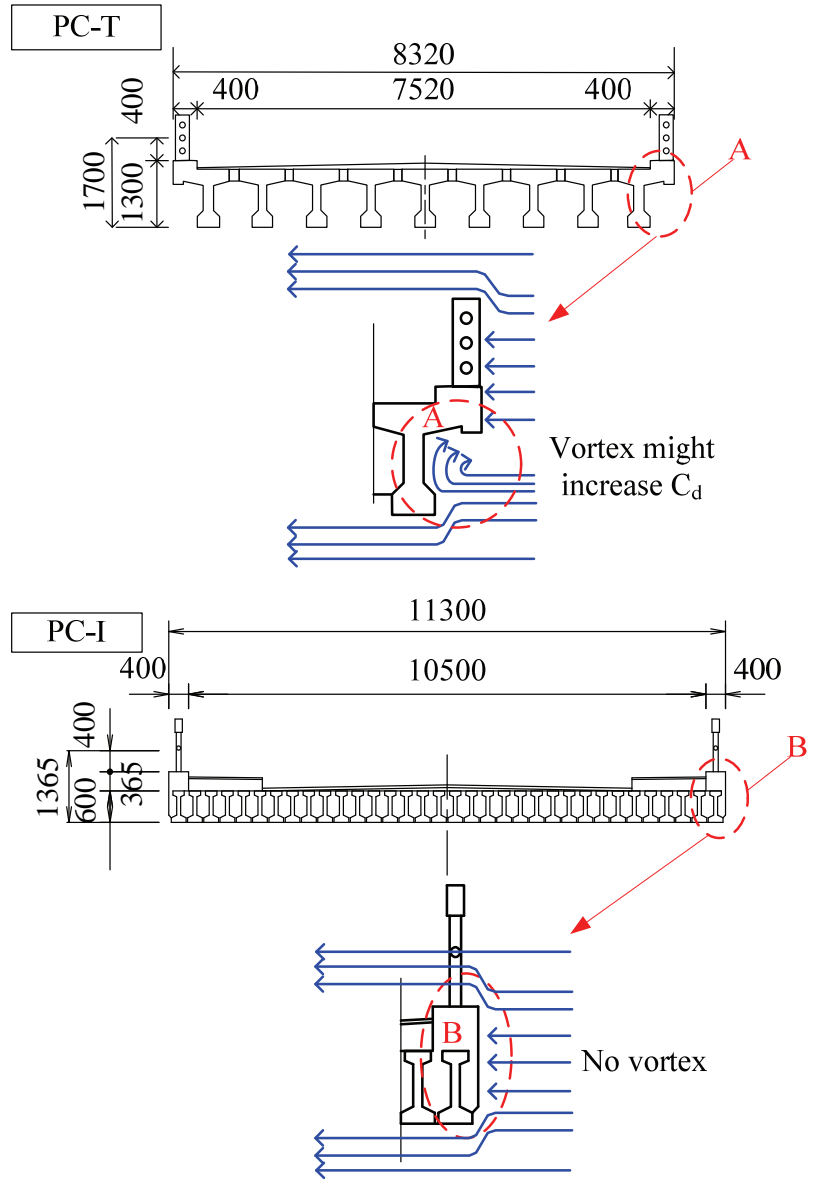

Fig.7 Reason why drag coefficient of PC-T deck might be estimated as too small.

situation, as shown in Fig.7, which gives the wave flow lines on PC-T and PC-I girders of similar scale, due to the vortex phenomenon at the groove part of girder, the tsunami force on PC-T can be increased, which can lead to a relatively large drag coefficient compared to that on the PC-I girder. Therefore, by using the same equation to compute drag coefficient, the drag coefficient of PC-T was estimated to be probably too small, ignoring the effect of vortex.

After that, the $\beta$ of steel girders are noted to be 
smaller than 1.0 and this indicates a weak tsunami resistance, as a result of small girder weights compared to concrete girders.

In summary, when velocity $6.0 \mathrm{~m} / \mathrm{s}$ was applied, girders with $\beta$ greater than 1.5 suffered Rank C damage and $\beta$ of girders that suffered Rank A damage are all smaller than 1.5. Thus, girders with $\beta$ values greater than 1.5 are considered to be safe. From the above analysis, it is known that the $\beta$ ratio is effective to evaluate the girder outflow, but the detailed mechanism of the girder outflow is still unclear. Therefore, in the following content, the video and numerical analyses were used to study the detailed tsunami characteristics (wave height and velocity time histories) and the outflow mechanism of bridge girders.

\section{TSUNAMI CHARACTERISTICS SHIZUGAWA TOWN}

In this chapter, Shizugawa located at Minamisanriku Town of Miyagi Prefecture was selected as an example to analyze the tsunami characteristics detailed.

Tsunami height and velocity histories are significant in analyzing tsunami damage. Thus, firstly the estimation of tsunami height and velocity variations in Shizugawa Town, with the application of videos recording the tsunami process, will be discussed. After that, the relationship between tsunami height and velocity variations will be studied. The results obtained in this chapter will be the basis for the evaluation of girders outflow in the next chapter.

After data gathering, two videos were used to estimate the tsunami height and velocity variations, and the video scope is shown in Fig.8. The estimation of tsunami height and velocity were conducted at the location near the Hachiman Bridge.

In Fig.9, first, the method for measuring tsunami height is introduced. Before measurement, some reference heights were estimated referring to the length of the girder span $(11.98 \mathrm{~m})$ : the height from the top of the guardrail to the static water level was estimated as $5.7 \mathrm{~m}$; the height from the top of building (a) to the top of the guardrail was estimated as $5.9 \mathrm{~m}$; the height from the top of the guardrail to the window of building-(a) is about $2.0 \mathrm{~m}$. Then during the tsunami progress, in video time, at 7:05s the tsunami reached the top of the bridge guardrail, from which we know the tsunami height was $5.7 \mathrm{~m}$. Then, at $7: 53 \mathrm{~s}$, the tsunami reached the window of the building (a) and the tsunami height at this time was noted to be about $7.7 \mathrm{~m}$. Besides, the corresponding video screen of measurements at 7:05 and 7:53s are plotted in Fig.10 and Fig.11.

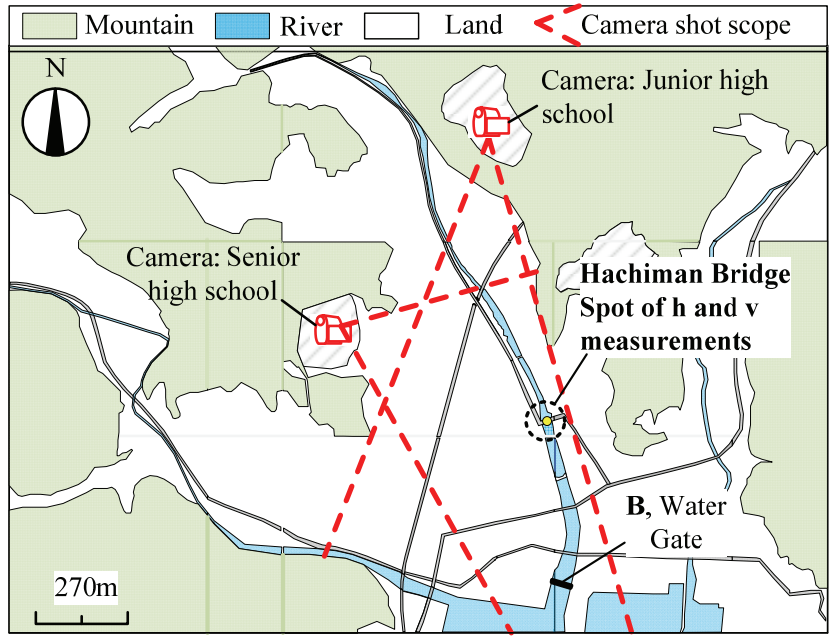

Fig.8 Study area.

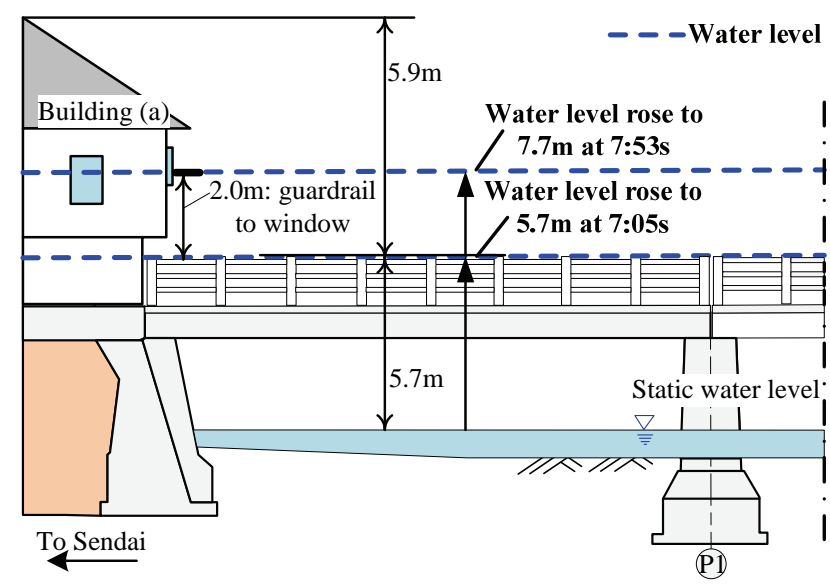

Fig.9 Side view of Hachiman Bridge.

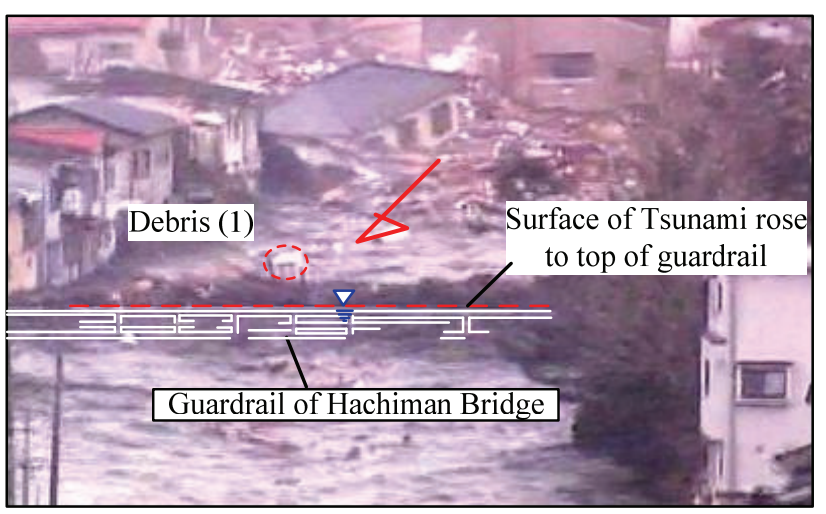

Fig.10 Tsunami wave at 7:05s.

Afterwards, using the same method, more tsunami heights at different time points at Hachiman Bridge were estimated and are summarized in Fig.12. At 5.4min., the tsunami reached the Hachiman Bridge. Before 9.0min., the tsunami height rose at the speed of $3.19 \mathrm{~m} / \mathrm{min}$. With the passage of time, the tsunami height ran up to the maximum $14.8 \mathrm{~m}$ at $12.0 \mathrm{~min}$., at a slow pace of $1.1 \mathrm{~m} / \mathrm{min}$. The average rising speed of tsunami height is estimated as $2.24 \mathrm{~m} / \mathrm{min}$. The tsu- 
nami height rose in a relatively slow pace indicating that the wave shape was not of the bore type.

Further, the investigations of the relationship between the tsunami height and the tsunami velocity will be shown. As presented in Fig.10 and Fig.11, much debris (debris (1) and debris (2)) were found flowing through the Hachiman Bridge. In the flow path of one piece of debris, two distinguished spots where the debris flowed through could be found. The distance between the two spots can be measured using Google Earth. The time at which the debris flowed through the two spots can be obtained by stopwatch. Lastly, the tsunami velocity is estimated by the ratio of the distance to the time span. As shown in Fig.13, using debris (1) and debris (2), measurements to get the tsunami velocity are explained. Based on the same method, velocities at different time points were estimated, in places near Hachiman Bridge.

After the wave height and velocity variations were estimated, the relationship between tsunami height and tsunami velocity was obtained and are shown in Fig.14. Here, we treat the velocity as 0 when the tsunami height is 0 . When the tsunami began to recede, the velocity was treated as 0 as well. Before the tsunami reached about $2 \mathrm{~m}$, the tsunami velocity rose to about $6 \mathrm{~m} / \mathrm{s}$. After a slight decrease, the velocity increased continually before the tsunami attacked the bridge girder. The maximum velocity $7.02 \mathrm{~m} / \mathrm{s}$ occurred when the tsunami was attacking the bridge girder. After the tsunami ran up to about $6 \mathrm{~m}$, the bridge was inundated and the tsunami velocity began to decrease and became about $4.86 \mathrm{~m} / \mathrm{s}$ (ave. of area D in Fig.14). After the tsunami height rose to about $12 \mathrm{~m}$, the velocity gradually decreased to 0 .

In Fig.14, two characteristics are observed. First one is that the tsunami velocity continued to increase to the maximum before the tsunami began to inundate the bridge girder. The second is that the tsunami velocity decreased suddenly when the bridge girder was inundated. With respect to the two characteristics, the following is observed: the girder top of Hachiman Bridge is the same level as the embankment top; thus, when the tsunami rose to girder top, it would overflow to the land area and that led to a decrease in tsunami velocity.

\section{EVALUATION OF GIRDER OUTFLOW OF HACHIMAN BRIDGE}

In this chapter, the author will discuss the outflow mechanisms of Hachiman Bridge in detail, based on the tsunami height and velocity variations. Hachiman Bridge, the location of which is shown in Fig.8, survived during the tsunami impact. The sectional

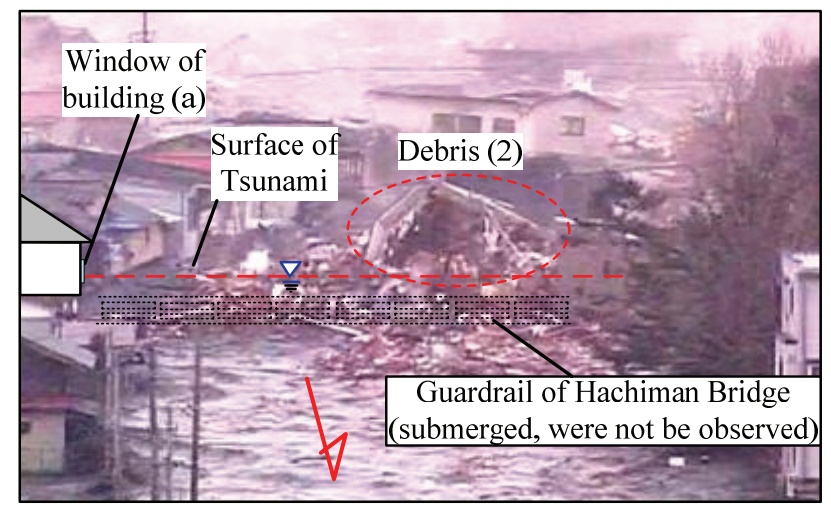

Fig.11 Tsunami wave at 7:53s.

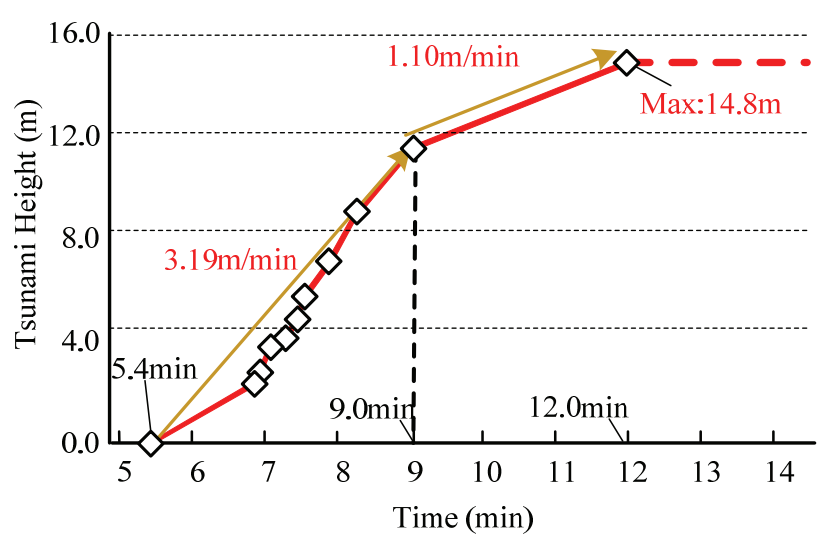

Fig.12 Time-dependent variations of tsunami height (Hachiman Bridge).

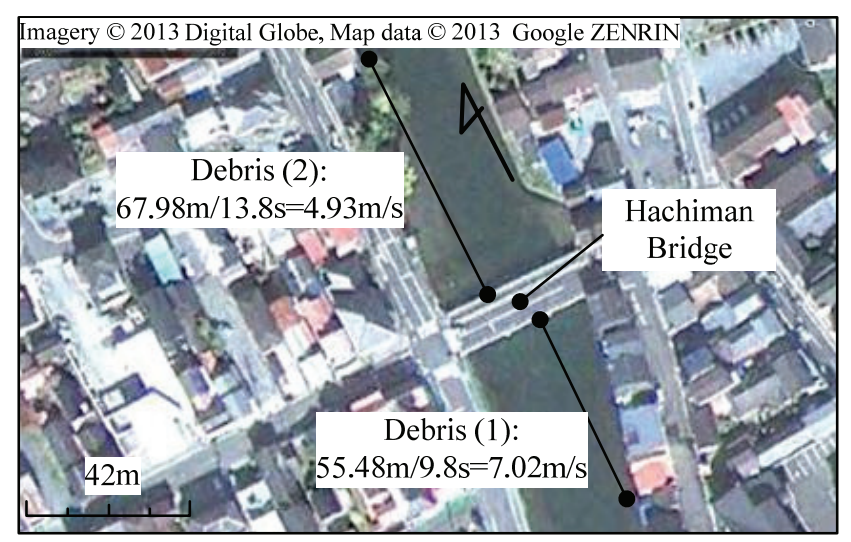

Fig.13 Estimation of tsunami velocity.

view of the bridge can be seen in Fig.16. The bridge girders belong to the PC-I type with a width of $8.2 \mathrm{~m}$, height of $1.069 \mathrm{~m}$.

From the tsunami height variation at Hachiman Bridge, as discussed in the previous chapter, the author propose two kinds of mechanisms at the time points when the tsunami simply hit the girder and when it submerged the girder totally. The images of the two mechanisms are shown in Fig.15 and Fig.16.

As shown in Fig.15, Mechanism 1 illustrates the condition when the tsunami only impacted on the girder. From the actual tsunami condition presented 
in Fig.10, the tsunami surface at the affected side was close to the top of the bridge guardrail. However, the tsunami at the upstream side only reached the bottom of the girder. The difference in tsunami height is about $1.7 \mathrm{~m}$, therefore the difference in water head is $1.7 \mathrm{~m}$. Mechanism 1 corresponds to the $\mathrm{C}$ area in Fig.14, in which the ave. velocity is estimated as $6.80 \mathrm{~m} / \mathrm{s}$.

Mechanism 2 is presented in Fig.16, when the bridge girder is inundated entirely. The tsunami surface at this time has a relatively flat shape without great difference in water head between the downstream side and the upstream side. Mechanism 2 corresponds to the area D in Fig.14, where the ave. velocity is estimated as $4.86 \mathrm{~m} / \mathrm{s}$.

In Mechanism 1 (Fig.15), the girder was acted by tsunami force and friction resistance. In the former calculation of the tsunami force by Eq. (1), only the hydrodynamic force was considered. In order to check whether it is reasonable that only consider hydrodynamic force when calculating tsunami force, the hydrostatic force is also considered ${ }^{7)}$, and the tsunamii force is computed by Eq. (8):

$$
F=\frac{1}{2} \rho_{w} C_{d} A v^{2}+C_{m} \rho_{w} A B \frac{d v}{d t}+\left(\rho_{w} g h_{1} A_{1}-\rho_{w} g h_{2} A_{2}\right)
$$

Where $F$ is the tsunami force containing hydrostatic force; $\rho_{w}$ is density of water $\left(1030 \mathrm{~kg} / \mathrm{m}^{3}\right) ; C_{d}$ is drag coefficient, which is calculated as 1.33 based on Eq. (6); $v$ is tsunami velocity $(\mathrm{m} / \mathrm{s}) ; A$ is projected pressure area of the girder in horizontal direction $\left(\mathrm{m}^{2}\right) ; C_{m}$ is inertia coefficient, which is assumed to be

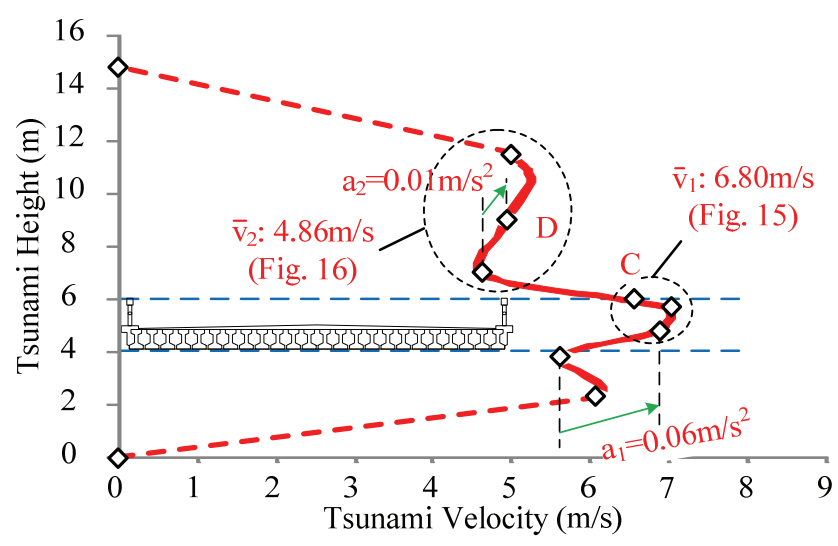

Fig.14 Relation between $v$ - $h$ (Hachiman Bridge).

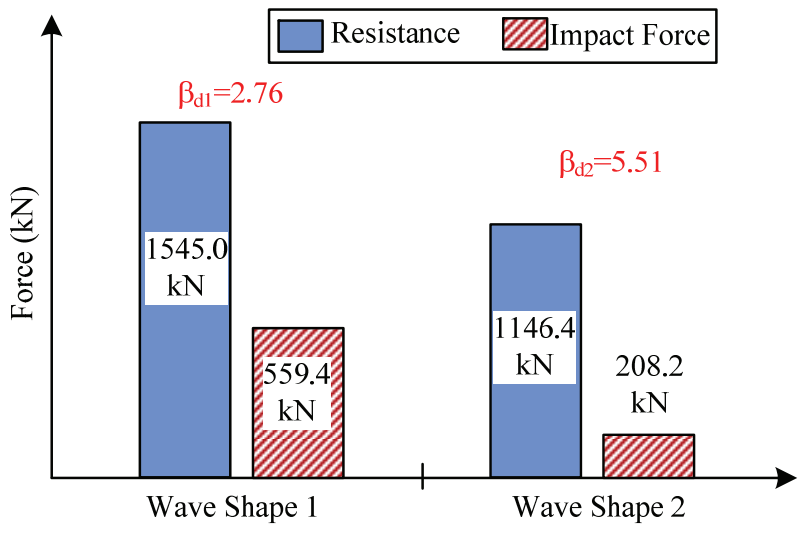

Fig.17 Calculation of $\beta$ of two wave shapes.

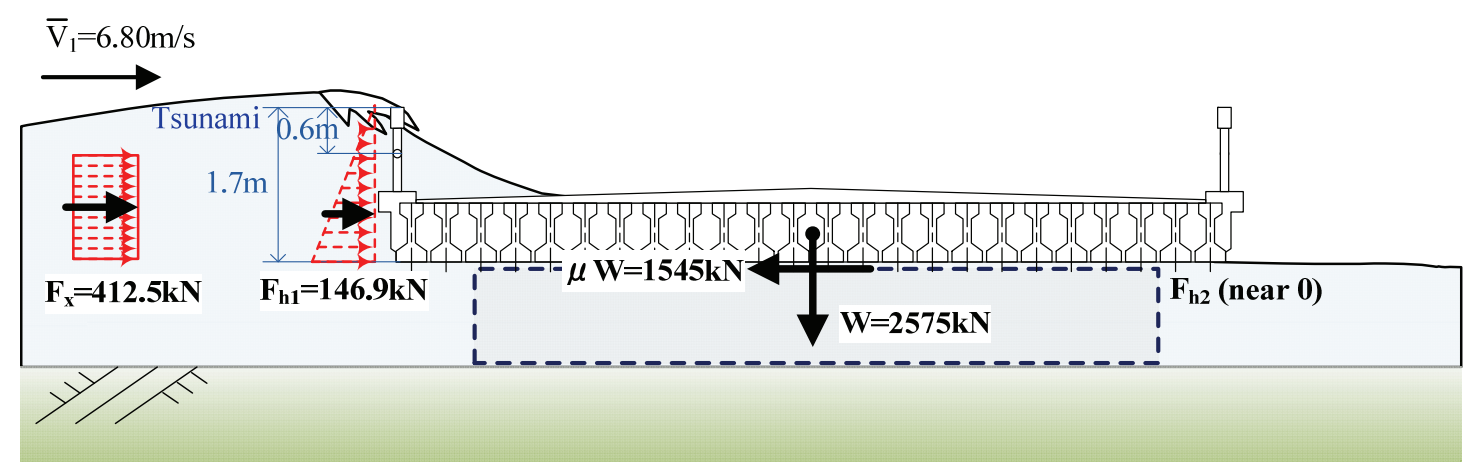

Fig.15 Mechanism 1 (tsunami only impacted on the bridge girder).

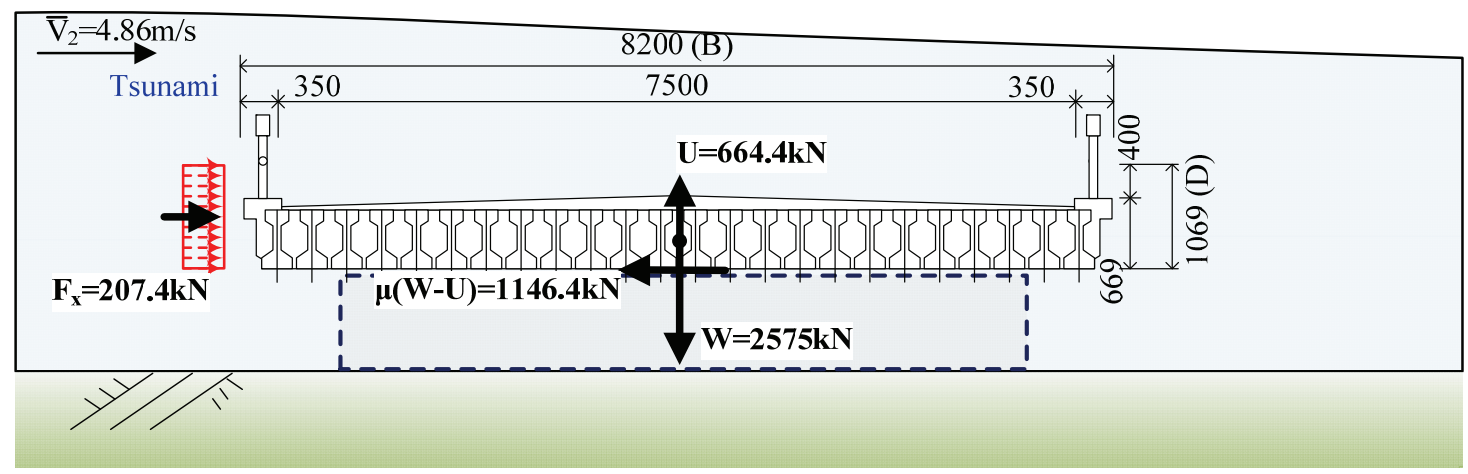

Fig.16 Mechanism 2 (bridge girder was entirely inundated). 
$1.0 ; B$ is bridge width $(\mathrm{m}) ; d v / d t$ is acceleration of tsunami velocity $\left(\mathrm{m} / \mathrm{s}^{2}\right) ; h_{1}$ and $A_{1}$ is water depth and the pressure area, respectively, at the downstream side of girder; $h_{2}$ and $A_{2}$ is the water depth and pressure area at the upstream side of the girder.

On the other hand, the friction resistance is calculated by former Eq. (2). Afterwards, corresponding to Mechanism 1, the girder outflow is evaluated by the $\beta_{d 1}$ (ratio of and friction resistance by Eq. (2) and tsunami force by Eq. (8)).

First, the hydrodynamic force is evaluated (first and second items at the right side of Eq. (8)). As shown in Fig.14, ave. velocity $6.80 \mathrm{~m} / \mathrm{s}$ and the greatest acceleration $a_{1}\left(0.06 \mathrm{~m} / \mathrm{s}^{2}\right)$ of area C are adopted. Thus, the hydrodynamic force is calculated as $412.5 \mathrm{kN}$. Second, the hydrostatic force is computed (the third item at the right side of Eq. (8)). As presented in Fig.15, the tsunami at the impacted side of the girder is assumed to attack only the top of the guardrail. The hydrostatic force is computed as $146.9 \mathrm{kN}$. For the upstream side of the girder, as the tsunami is attacking only the bottom of the bridge girder, the hydrostatic force is ignored. Thus, the hydrostatic force is calculated as $146.9 \mathrm{kN}$. The hydrodynamic force $(412.5 \mathrm{kN})$ is about 2.81 times of the hydrostatic force $(146.9 \mathrm{kN})$. This is the reason why in the first chapter, when computing the tsunami force, the author only considered hydrodynamic force (Eq. (1)). Further, the resistance of the girder and the $\beta$ can be computed by the former equations. For Mechanism 1, the resistance is computed as $1545 \mathrm{kN}$, which is $2.76\left(\beta_{d 1}\right)$ times larger than the tsunami force $(559.4 \mathrm{kN})$.

With respect to Mechanism 2, as illustrated in Fig.16, the difference in water head is ignored and only the hydrodynamic force is considered. Further, as the girder was entirely inundated, the buoyancy was considered when computing girder resistance. Thus, corresponding to Mechanism 2, the $\beta_{d_{2}}$ (ratio of the friction resistance by Eq. (3) to the tsunami force by Eq. (8)) is used to evaluate girder outflow.

From Fig.14, the average velocity $4.86 \mathrm{~m} / \mathrm{s}$ and greatest acceleration $0.01 \mathrm{~m} / \mathrm{s}^{2}$ in area $\mathrm{D}$ are used for the computation of the tsunami force. The resistance is computed as $1146.4 \mathrm{kN}$, which is 5.51 times $\left(\beta_{d 2}\right)$ greater than the tsunami force $(208.2 \mathrm{kN})$.

In summary, as illustrated in Fig.17, both $\beta_{d_{1}}$ and $\beta_{d 2}$ ratios show the large levels (2.76 and 5.52), which explains the survival of the girder.

\section{OBSERVED DAMAGE OF UTATSU BRIDGE}

For the second example, the outflow mechanism of Utatsu Bridge is analyzed. Before that, the outflow condition of Utatsu Bridge is described.

\section{(1) Introduction of Utatsu Bridge}

For simpler analysis, the author assign numbers for all girders and piers from Sendai City side to Kesennuma City side. As shown in Fig.18, 12 girders are numbered from S1 to S12 while the 11 piers are numbered from P1 to P11.The Utatsu Bridge is made of three types of prestressed concrete girders (S1 S2: $40.7 \mathrm{~m}$, post tensioning; S3 S7: $14.4 \mathrm{~m}$, pretensioning; S8 S12: $29.9 \mathrm{~m}$, post tensioning). The piers had been retrofitted with reinforced concrete jackets before tsunami came.

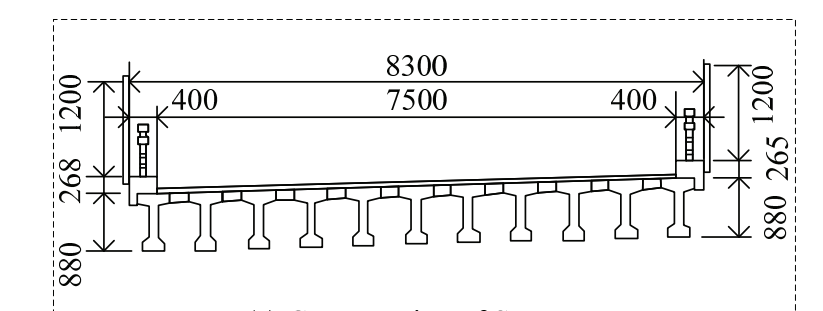

(a) Cross section of $\mathrm{S} 3 \sim \mathrm{S} 7$

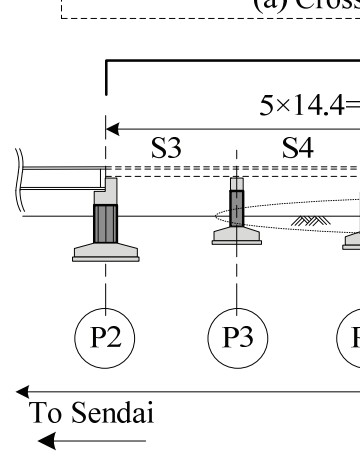

$$
\uparrow
$$

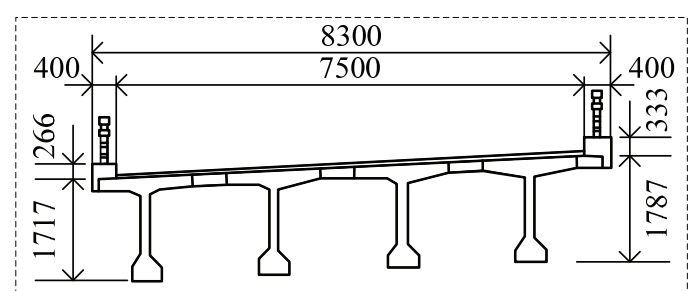

(b) Cross section of $\mathrm{S} 8 \sim \mathrm{S} 12$ $\uparrow$ 


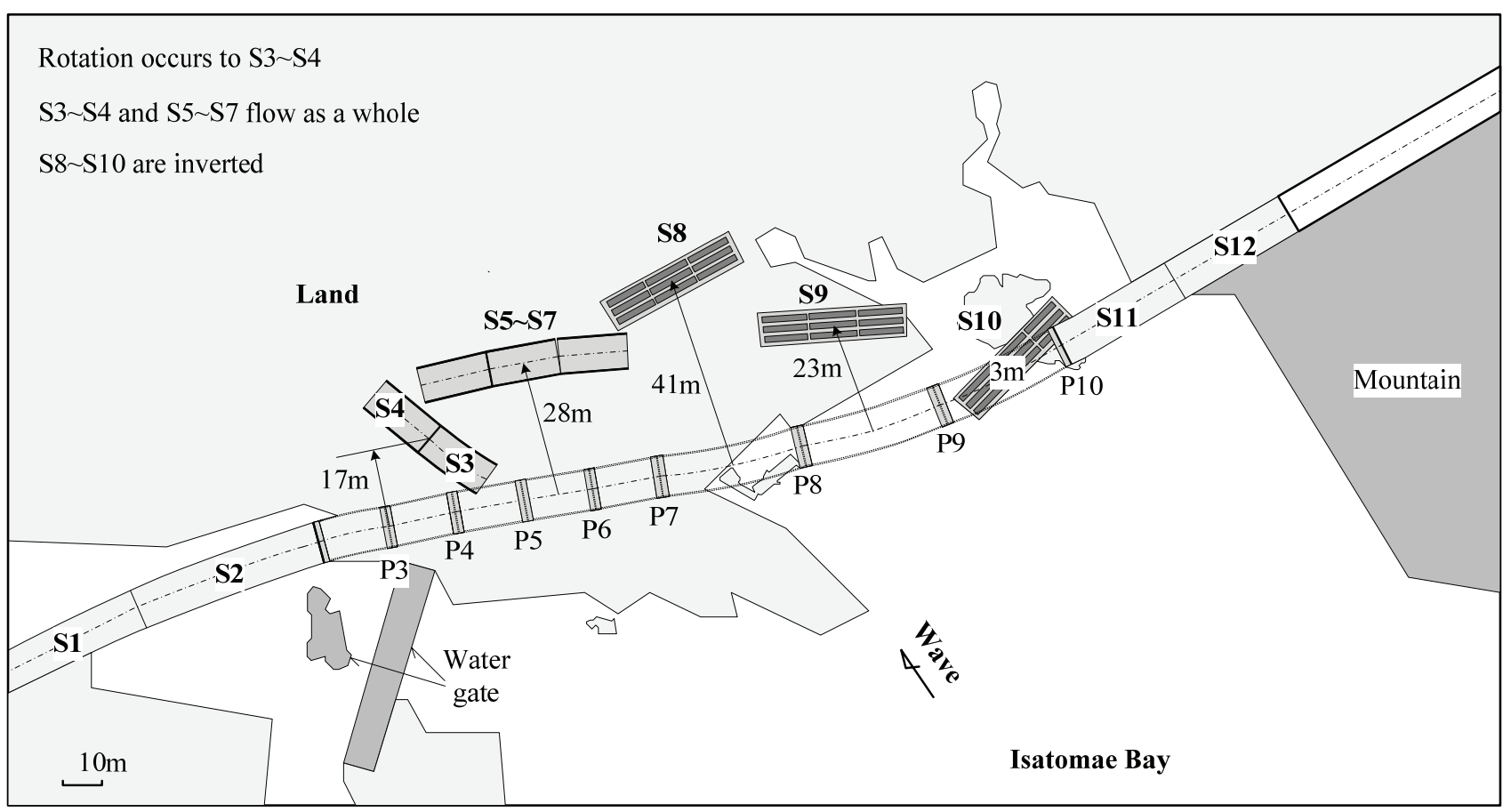

Fig.19 Outflow condition of Utatsu Bridge.

\section{(2) Outflow condition of girders}

As shown in Fig.19, based on the investigation, the effect of the wave surge is particularly devastating for girders, namely middle girders S3 S10 were moved off their supports under the wave-induced load. However, the girders S1, S2, S11 and S12 survived the tsunami hit. The middle girder (S8) suffered greater displacement than the side girders (S3 S4, S10). S3-S4 and S5-S7 were also displaced while S8 S10 were inverted by wave uplift. S3-S4 were also rotated by the wave effect.

Unlike the damaged girders, all piers withstood the tsunami force and did not collapse. However, the foundation soils from P3 to P7 suffered serious scouring (Fig.18).

\section{OUTFLOW EVALUATION OF S9 BY VIDEO ANALYSIS}

In order to understand the process of tsunami propagation, and infer the tsunami mechanisms on bridge girders, a video recording of the tsunami hit was used in the analysis.

The video recording used was shot by a resident of the Isatomae area of Minamisanriku town. The start time of the video was around 31min. after the occurrence of the earthquake and based on the video, the wave height and velocity were measured at some time points.

\section{(1) Wave velocity measurement}

As shown in Fig.20, in the video record, only the

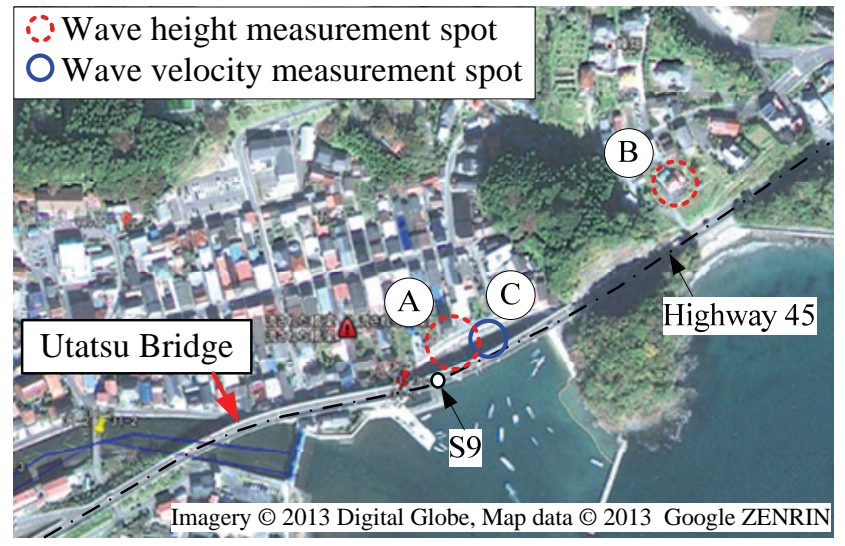

Fig.20 Spots of video analysis.

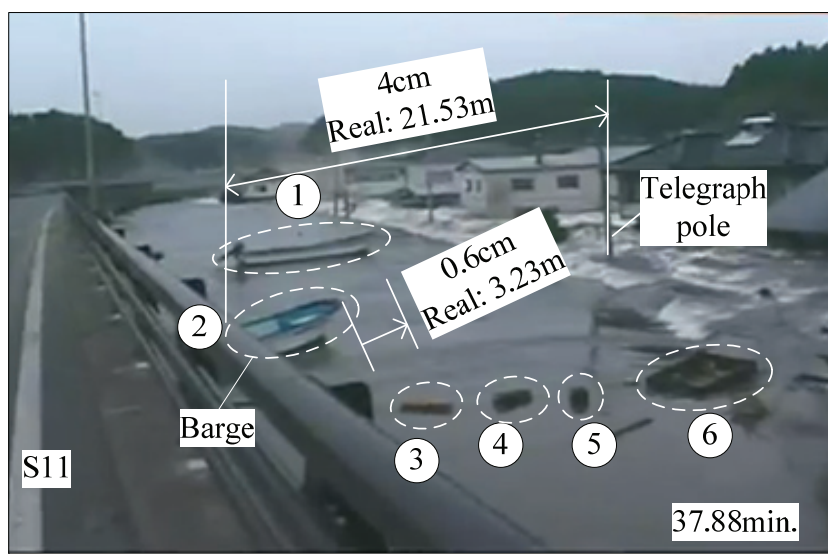

Fig.21 Sample of debris for wave velocity measurement.

tsunami at Spot C near S9 can be observed clearly, thus the wave velocity is measured here and the outflow of S9 is analyzed. 


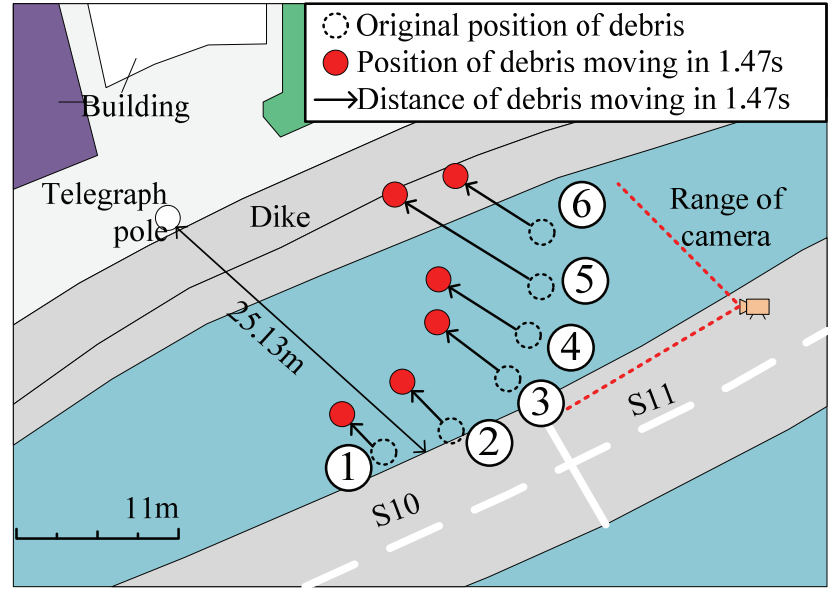

Fig.22 Displacement measurement of debris of No. 1 6.

By the same method as the velocity estimation at Shizugawa town, the wave flow velocity at Utatsu Bridge is measured. For example, as shown in Fig.21, the video screen displays the tsunami flow at $37.88 \mathrm{~min}$. after the earthquake. From the video, six pieces of floating debris (No. 1 6), including barges and wood, are observed. The bridge guardrail and telegraph pole can be confirmed in a satellite photo of Google Earth and the distance between them is measured as $25.13 \mathrm{~m}$ (Fig.22), while in the video screen, the corresponding distance from the guardrail to the telegraph pole is estimated as $4 \mathrm{~cm}$. Therefore, the scale of the video screen is about $1 / 538$. For debris No.2, at the time span of $1.47 \mathrm{~s}$, it flows $0.6 \mathrm{~cm}$ on screen, namely the real displacement is $3.23 \mathrm{~m}$, and the flow velocity of No. 2 is computed as $2.20 \mathrm{~m} / \mathrm{s}$. The flow velocities of the other five pieces of debris are also computed (flow distances are plotted in Fig.22), as shown in Table 3. The ave. flow velocity of debris is $3.79 \mathrm{~m} / \mathrm{s}$, which is regarded as the wave velocity at S9 in $37.88 \mathrm{~min}$. Afterwards, the ave. wave velocity at S9 in 39.63min. is measured as $4.39 \mathrm{~m} / \mathrm{s}$.

\section{(2) Wave height measurement}

After checking the video, the author notes that the wave height at Spots A and B (Fig. 20) can be measured, by contrasting the water level and the height of local structures. The estimating method for wave height is proposed in this section. The static water level before the tsunami arrival is T.T.- $0.9 \mathrm{~m}$ (T.T. level: astronomical tide) and the wave height in the following content is described based on T.T. level.

The measurement at Spot A is described as an example. As shown in Fig.23, through field survey, the top of the building close to the coastal line is measured as $2.3 \mathrm{~m}$ (measured by meter ruler, accuracy: $0.1 \mathrm{~m}$ ). From the video, it can be observed that
Table 3 Measurement result of wave velocity at $37.88 \mathrm{~min}$.

\begin{tabular}{|c|c|c|c|c|}
\hline \multirow{2}{*}{ No. } & \multirow{2}{*}{ Debris type } & Distance & Time & Velocity \\
\hline & & (m) & (s) & $(\mathrm{m} / \mathrm{s})$ \\
\hline 1 & Barge & 3.23 & 1.47 & 2.20 \\
\hline 2 & Barge & 2.79 & 1.47 & 1.90 \\
\hline 3 & Driftwood & 5.38 & 1.47 & 3.66 \\
\hline 4 & Black object & 6.46 & 1.47 & 4.39 \\
\hline 5 & Black object & 9.15 & 1.47 & 6.22 \\
\hline 6 & Box & 6.46 & 1.47 & 4.39 \\
\hline \multicolumn{4}{|c|}{ Average } & 3.79 \\
\hline
\end{tabular}

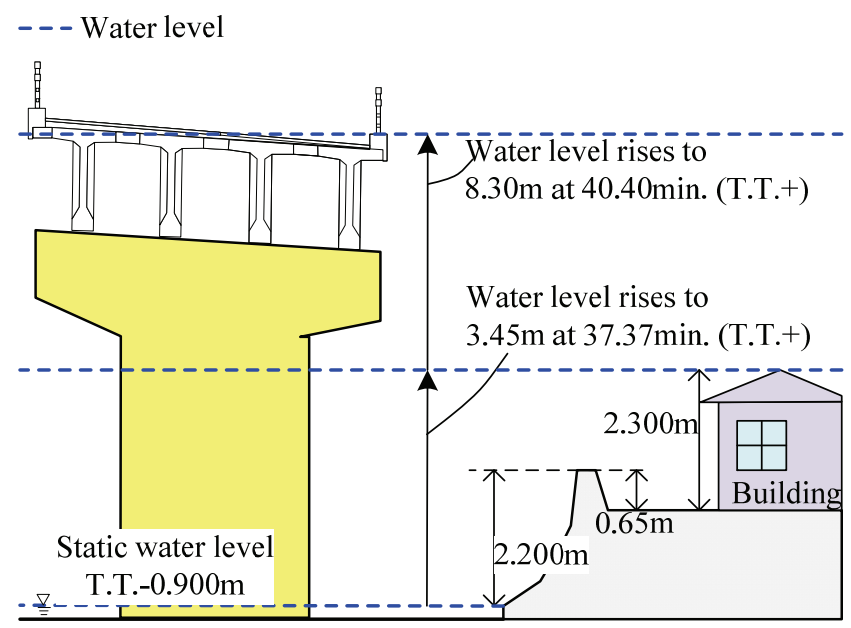

Fig.23 Measurement of wave height.

Table 4 Measurement results of wave height (T.T.+).

\begin{tabular}{|c|c|c|c|}
\hline \multicolumn{2}{|c|}{ Spot A } & \multicolumn{2}{c|}{ Spot B } \\
\hline time & Wave height & time & Wave height \\
\hline (min.) & $(\mathrm{m})$ & (min.) & (m) \\
\hline 31.00 & -0.90 & 39.95 & 8.3 \\
\hline 31.73 & -0.90 & 42.30 & 13.7 \\
\hline 35.40 & -0.40 & & \\
\hline 37.37 & 3.45 & & \\
\hline 39.07 & 5.30 & & \\
\hline 40.40 & 8.30 & & \\
\hline 41.38 & 10.10 & & \\
\hline 42.35 & 11.30 & & \\
\hline 42.82 & 11.70 & & \\
\hline
\end{tabular}

at $37.37 \mathrm{~min}$. after the earthquake, the roof of the building is just inundated. Since the height of the building is measured as $2.3 \mathrm{~m}$ from the ground, the water level this time is identified as $3.45 \mathrm{~m}$. Furthermore, through design drawing, the top height of the bridge girder is confirmed as $8.3 \mathrm{~m}$. The video shows that at $40.40 \mathrm{~min}$. after the earthquake, the girder top is just submerged. Thus, the wave height 


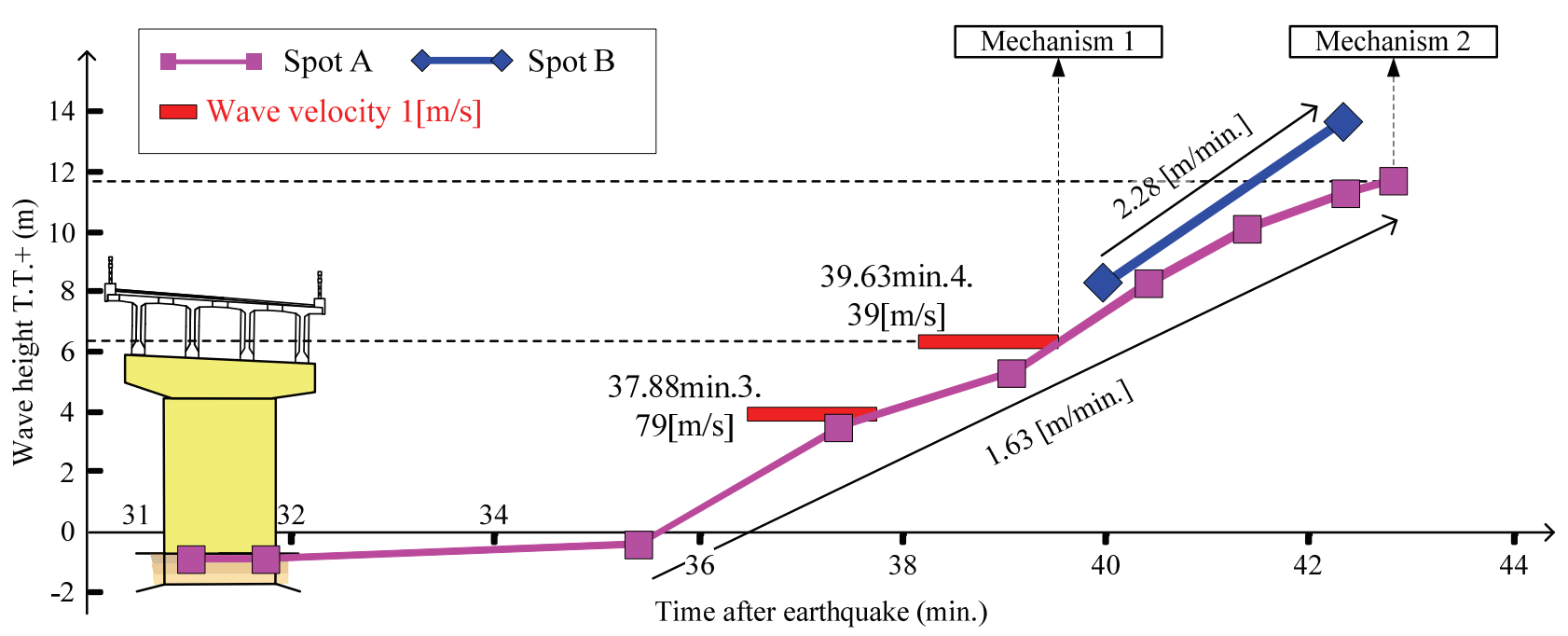

Fig.24 Wave velocity and height histories from video.

this time is identified as $8.3 \mathrm{~m}$.

By the same method, more wave heights at other time points were measured at Spot A and Spot B, as shown in Table 4.

In summary, the measured wave velocities and heights are plotted in Fig.24. From the wave height data, the rise speed of wave height is computed. For Spot A, from 35.40min. to $42.82 \mathrm{~min}$., the ave. rise speed was $1.63 \mathrm{~m} / \mathrm{min}$., while for Spot $B$, from $39.95 \mathrm{~min}$. to $42.30 \mathrm{~min}$., the ave. rise speed was $2.28 \mathrm{~m} / \mathrm{min}$. Therefore, it is clear that the wave height rose quite slowly and it is judged that the wave was not the bore type.

\section{(3) Outflow evaluation of S9}

In view of the above flooding characteristics of the bridge girder, similar to Hachiman Bridge, two types of mechanisms are determined. Since S9 is located at measurement Spot A, it is selected as the sample to analyze the mechanism. As shown in Fig.25, at 39.63min., it is observed that the tsunami only began to impact on S9 at the height of about $5.8 \mathrm{~m}$. Considering the mechanism condition, similar to the flooded condition of Mechanism 1 of Hachiman Bridge, since the girder was not submerged totally, S9 was mainly affected by the tsunami force $(F)$, gravity force $(W)$ and friction resistance $(S)$ from the pier respectively (defined as Mechanism 1'). Corresponding to Mechanims 1', $\beta_{1}$ ' (ratio of friction resistance by Eq. (2) to tsunami force by Eq. (1)) is used to evaluate girder outflow. Here, the hydrodynamic force Eq. (1) was used to calculate tsunami force, because in Chapter 4, it is concluded that compared with hydrostatic force was very small and was ignored.

With the rise of water level, as shown in Fig.26, at $42.82 \mathrm{~min}$., the wave flooded S9 totally. Similar to the flooded condition of Mechanism 2 of Hachiman

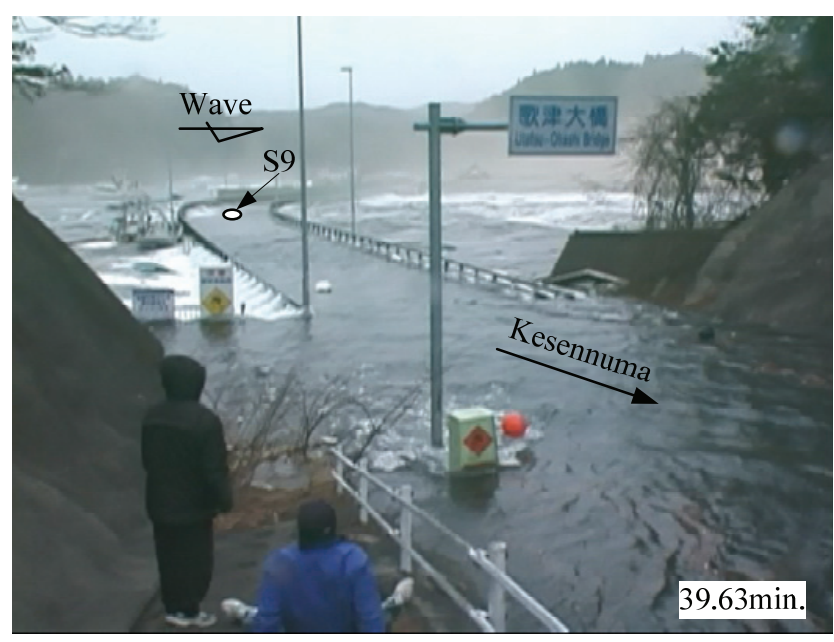

(a) Water level at 39.63min.

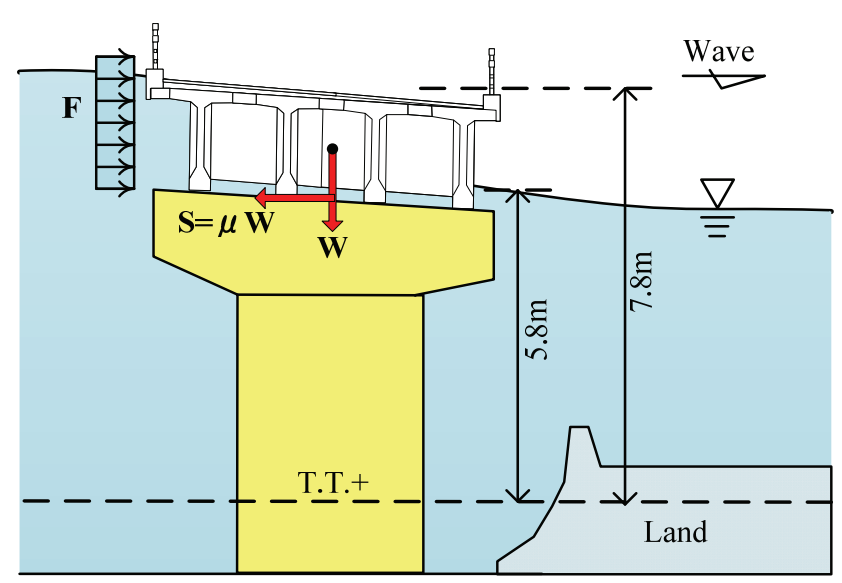

(b) Corresponding mechanism 1' at 39.63min.

Fig. 25 Analysis of mechanism at 39.63min.

Bridge, S9 was also affected by buoyancy $(U)$ additionally and the buoyancy reduced the friction resistance significantly (defined as Mechanism 2'). 
Corresponding to Mechanim 2', $\beta_{2}$, (ratio of friction resistance by Eq. (3) to tsunami force by Eq. (1)) is used to evaluate girder outflow.

For the both mechanisms, when calcualting tsunami force, from video analysis, the flow velocity $4.39 \mathrm{~m} / \mathrm{s}$ (39.63min., Fig.24), was used.

The author computed the $\beta_{1}$, and $\beta_{2}$, to compare the friction resistance and the tsunami force and the calcualtion result is illustrated in Fig.27. Comparing the friction resistances of two mechanisms, it is obvious that due to the buoyancy effect, a big gap occurred and when S9 was flooded totally, the friction resistance was relatively weak so S9 flowed out. This can be confirmed by the video recording: at $43.30 \mathrm{~min}$., the spray caused by the movement of girders were observed.

\section{OUTFLOW EVALUATION BY 2-D NUMERICAL ANALYSIS}

From the above video analysis, the tsunami characteristics near S9 may be roughly studied. However, it is impossible to get the tsunami characteristics of other areas except for S9. Thus, in this chapter, a two-dimensional numerical analysis is carried out for a detailed analysis of the tsunami characteristics for the whole area of Utatsu town.

\section{(1) Condition of numerical analysis}

In the simulation of the tsunami propagation, the nonlinear long wave theory is applied. In order to accurately simulate the wave height at inundated areas using the long wave theory equation, the item of bottom friction (ocean) and the items of advection are taken into account.

The Fujii•Satake Model (Ver.4.6) ${ }^{8)}$, which has 40 faults, is used as the original model of seismic wave source. There are eight areas for simulation analysis: A, B, C, D, E, F, G and H (Fig.28). The Utatsu Bridge is located at the center of Area H. From Area A to $\mathrm{H}$, the mesh size of the area has a threefold decrease and the maximum mesh size is as large as $4374 \mathrm{~m}$ (Area A) while the minimum mesh size is $2 \mathrm{~m}$ (Area $\mathrm{H}$ ). From Area A to $\mathrm{H}$, the areas gradually approach the Utatsu Bridge and the mesh accuracy of area gets higher and higher.

When interpolating terrain data into simulation areas, the isoparametric element method with nine points is applied. For the land area, the minimum mesh size of terrain data applied is $5 \mathrm{~m}$ (Base map information download service by Geospatial Information Authority of Japan) while for the sea area, the accuracy of depth contour data used is 10m (Digital bathymetric data by Marine Information Research Center). When combining the terrain data of the land

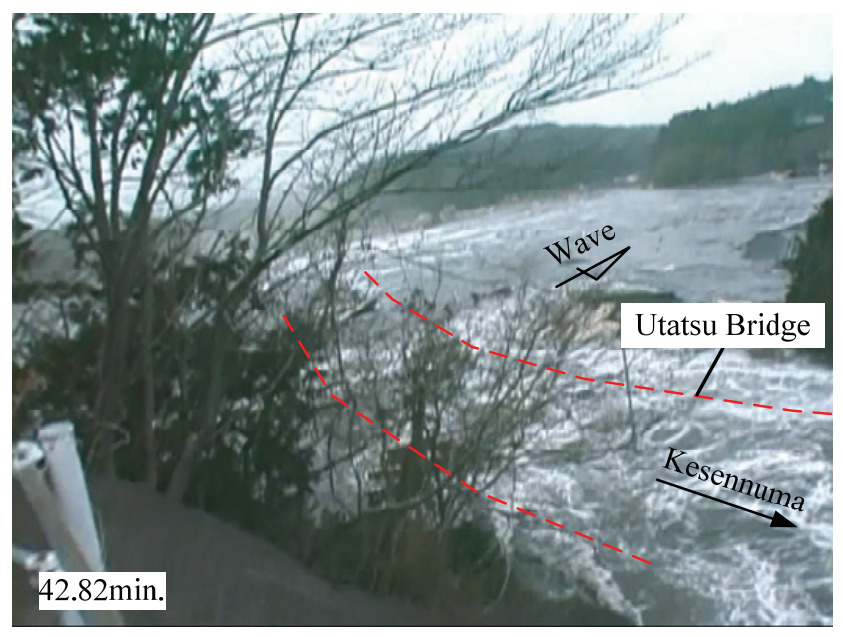

(a) Wave level at $42.82 \mathrm{~min}$.

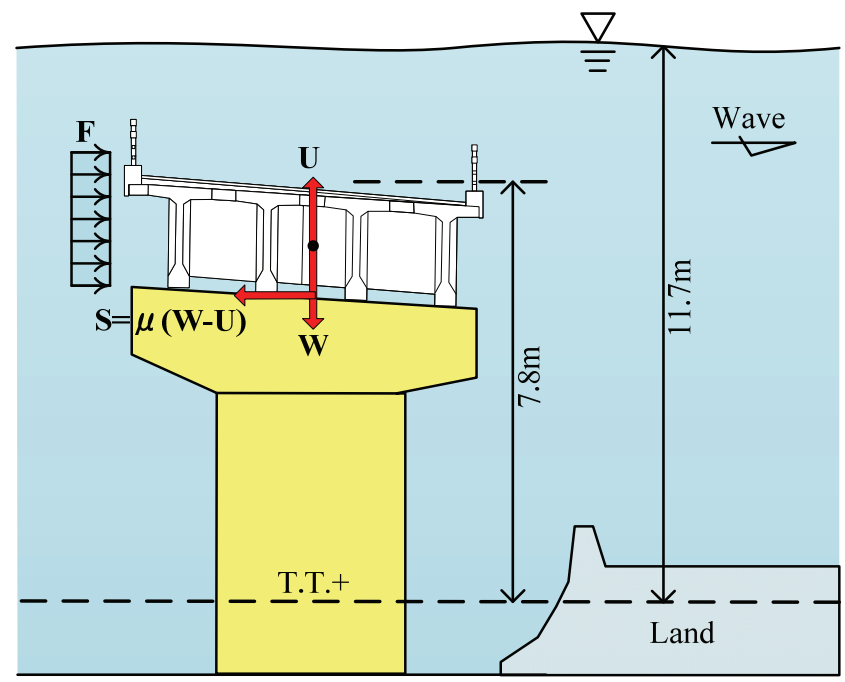

(b) Corresponding mechanism 2' at 42.82min.

Fig. 26 Analysis of mechanism at 42.82min.

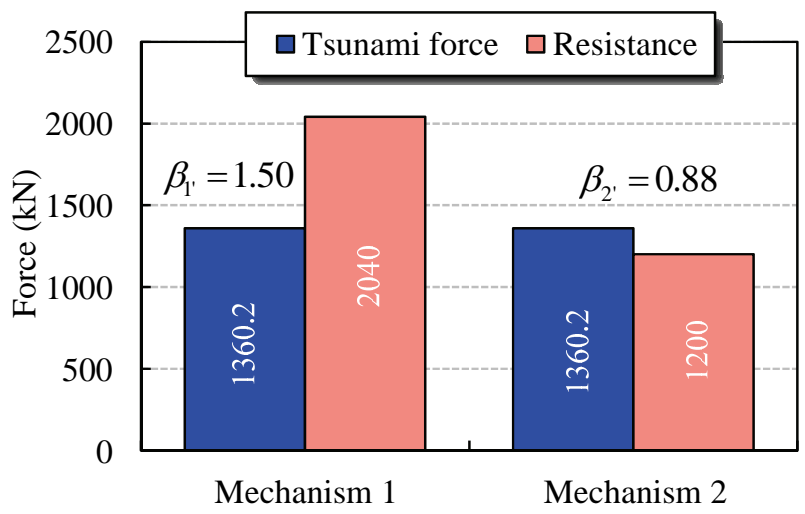

Fig. 27 Outflow evaluation of S9 by video analysis.

and sea areas, the Kriging Interpolation method is applied. Since the minimum size of terrain data on land applied is $5 \mathrm{~m}$, the accuracy of land simulation is $5 \mathrm{~m}$. 

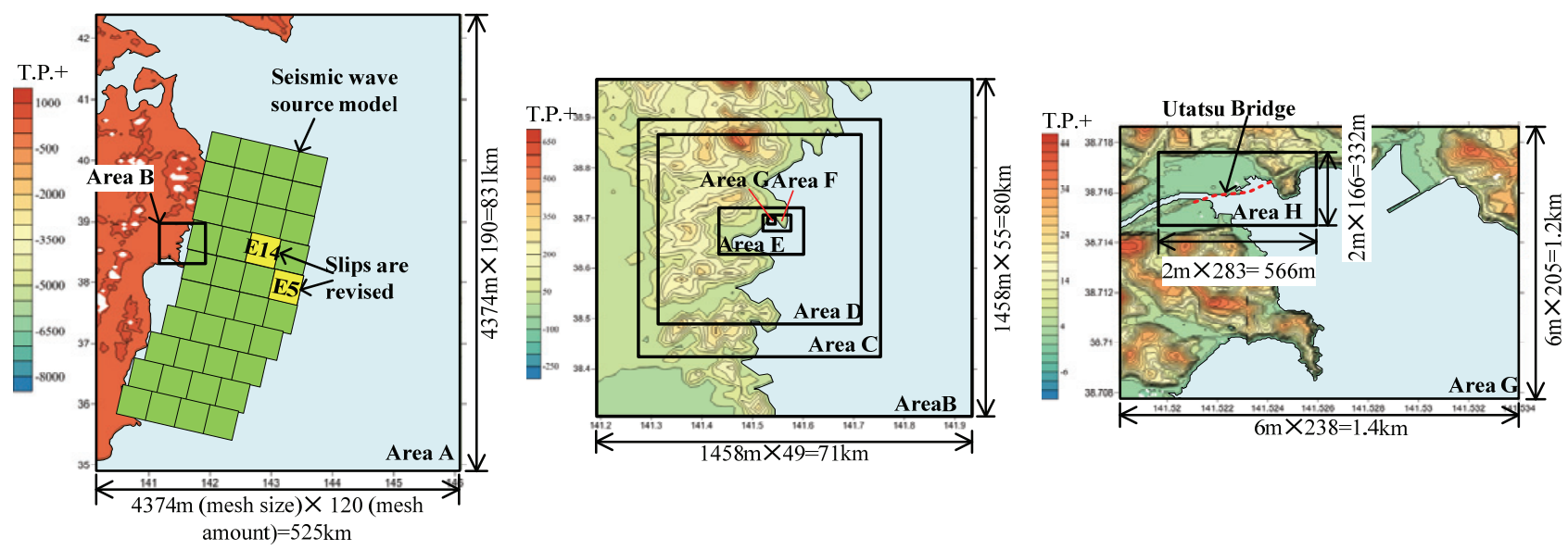

Fig.28 Association of simulation areas.

For the roughness data, based on the simulation guide $^{9)}$, the medium density of building area, forests, farmland and water area are defined as 0.060, 0.030, 0.020 and 0.025 , respectively.

After the completion of set of parameters, the simulation can be conducted. The resulting tsunami within one hour after the earthquake is simulated and the simulating time cell is $0.001 \mathrm{~s}$. Besides, for the initial simulation condition, the seafloor foundation displacement is set based on the Mansinha and Smylie Method ${ }^{10)}$.

In order to get the simulation result closest to the real situation, the slip values of some faults should be modified. Here, the author made modifications according to four principles. First, fewer number of faults as possible should be made; second, after modification, the earthquake moment magnitude must be kept close to the original 9.0; thirdly, the simulation wave height variation trend at the location of GPS wave gauge should be modified to roughly coincide with the observed result by wave gauge; fourth, the simulation of the inundation area should be modified to coincide with the survey result as much as possible.

Thus, as shown in Fig.28(a), the author selected two faults (E5 and E14), the slip values of which need bigger modification than the others because the simulation results (such as outputs of wave height and velocity) change more significantly if a fault with bigger slip is modified. This way, the author modify the smallest number of faults to allow the simulation results to properly display real tsunami characteristics (as discussed in the following section). For the E5 fault, the slip value $34.73 \mathrm{~m}$ is changed to $60 \mathrm{~m}$ while for the E14 fault, the slip value $25.71 \mathrm{~m}$ is modified as $40 \mathrm{~m}$. After slip modification, the earthquake magnitude changes from 8.99 to 9.02, which kept at roughly 9.0.

After the modification, it is found that the variations in the simulation wave heights at the GPS

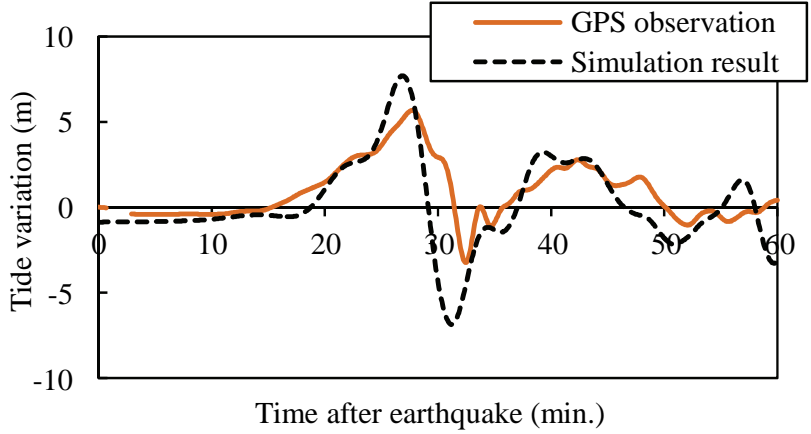

Fig.29 Comparison of tide varitions.

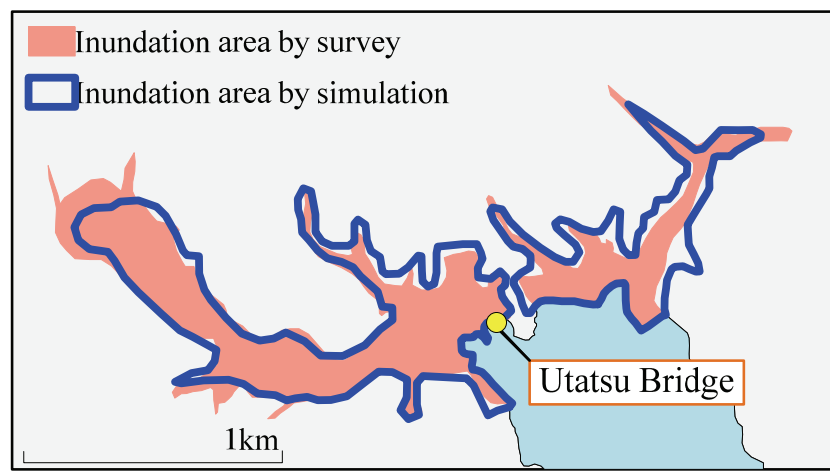

Fig.30 Comparison of inundation areas.

gauge set at the ocean north of Miyagi Prefecture ${ }^{11)}$ roughly coincide with the observed historical data (Fig. 29). The maximum wave heights of the simulation and the observation occur close to the time points. Fig.30 plots the simulation maximum inundation area in Utatsu town. For comparison, the real inundation area by Geospatial Information Authority of Japan ${ }^{12)}$ is also outlined. It is obvious that the simulation inundation area is close to the real result. Therefore, the simulation appears to be reasonable.

\section{(2) Simulation result}

In this section, the analysis of the simulation result 
is discussed.

First, the tsunami process is illustrated in the water level and velocity contour graphs. The tsunami comes to the coastal line at $20.67 \mathrm{~min}$., as shown in Fig.31. The tsunami comes the southeast and because it is blocked by mountain $\mathrm{A}$, the wave is divided into two branches. Both the wave height and velocity show small levels. Afterwards, at $30.50 \mathrm{~min}$., the tsunami flows to the inland residential area (Fig.32). The wave head is divided into two branches, and one branch flows to the residential area while the other flows into Isatomae river. Due to the obstruction posed by the water gate, the velocity and height of the wave head in front of the water gate are smaller than those in the other parts. The tsunami height this time is less than $2.0 \mathrm{~m}$ (T.T.+) and cannot affect the bridge girders. Next, at $38.50 \mathrm{~min}$., the tsunami at the bridge location rises to about $7.0 \mathrm{~m}$ (T.T.+) and begins to hit the bridge girders (Fig.33). It is noted that the wave velocity at the middle part of the bridge (arrows in No.2 box) is relatively greater than that in the bridge end parts (arrows in No.1 and No.3 boxes), because the water gate and mountain A block the flow of waves at No.1 and No.3 boxes, respectively. Thus the damage to the bridge middle spans is more serious than that in the end spans. Furthermore, the maximum velocity happens at No.4, because the wave overflows and dives down from the road surface (image of the road surface can be checked in Fig.34).

Second, the analysis of wave height and velocity variations in chosen spots is carried out. As shown in Fig.34, the author analyzed the simulation results of seven spots. Spot 1 and Spot 7 are $100 \mathrm{~m}$ and $200 \mathrm{~m}$ far away from the coastal line, respectively. For example, the wave height and velocity histories of Spot 3 are plotted in Fig.35. It is obvious that the tsunami reaches the bridge at about 20min., and after $37 \mathrm{~min}$., the wave height and velocity increase very fast. The maximum wave height and velocity are $18.8 \mathrm{~m}$ and $4.06 \mathrm{~m} / \mathrm{s}$, respectively.

After that, the characteristics of the tsunami height variation from coast to land were analyzed. The author checked the variations in tsunami heights of Spot 1 to 7 from 37.91min. (when the tsunami only flooded Spot 7) to 43.33min. (when the tsunami height rises to the maximum). As a result, the following characteristics were discovered: as shown in Fig.36, before $38.25 \mathrm{~min}$, the wave height at the sea area is found to be greater than that at the land area; in other words, the wave power at the sea is larger than that at the land area. Thus, the ave. wave velocity of Spot 1 to 7 increases continuously. However, after $39.25 \mathrm{~min}$., the wave heights of all spots show the same level; in other words, there is no difference between the wave power in the sea and land areas.

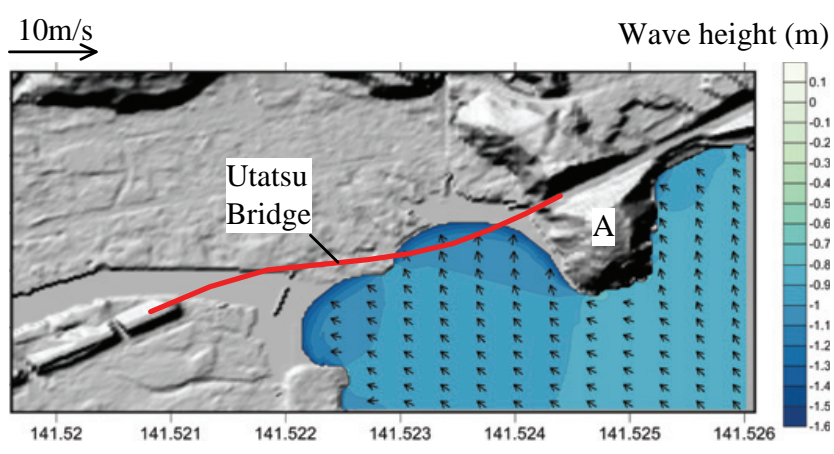

Fig.31 Wave height and velocity distribution (20.67min.).

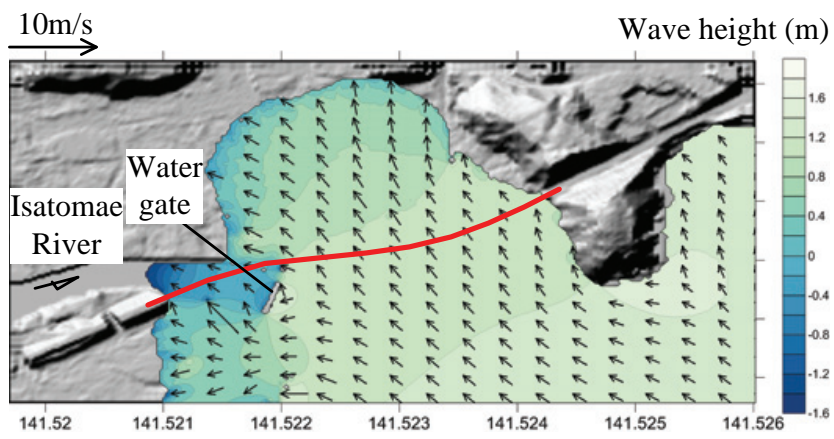

Fig.32 Wave height and velocity distribution (30.50min.).

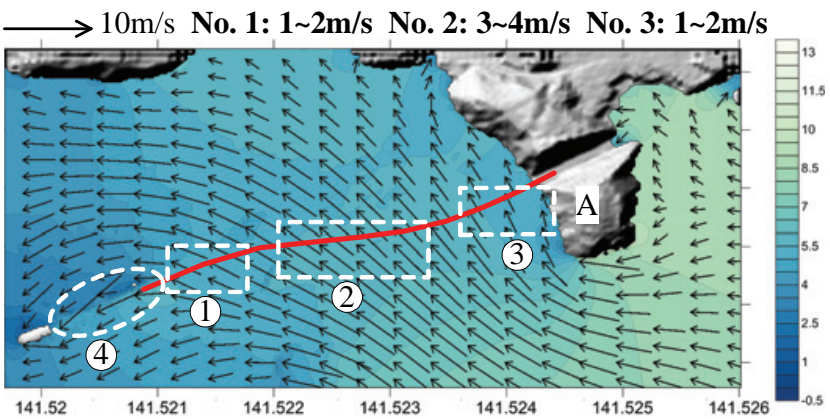

Fig.33 Wave height and velocity distribution (38.50min.).

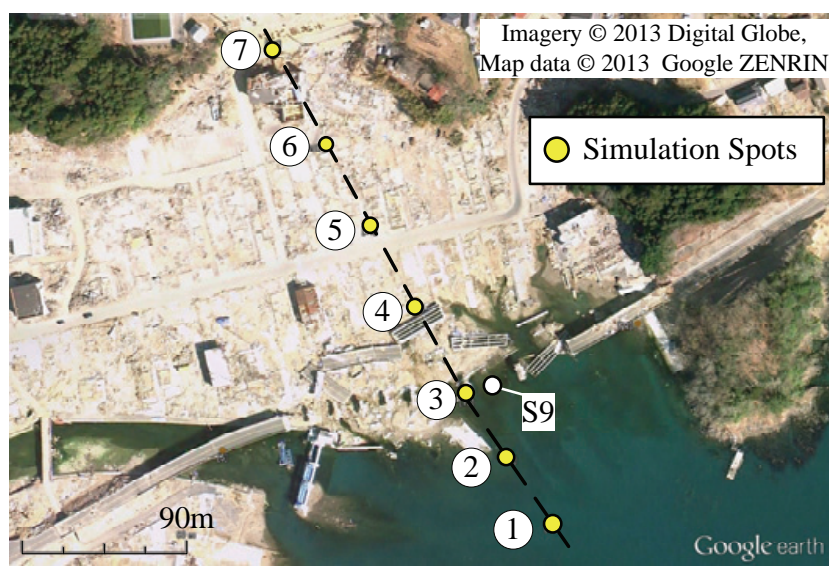

Fig.34 Chosen simulation spots. 
Therefore, the average wave velocity of Spot 1 to 7 stops increasing.

\section{(3) Comparison of simulation result and video result}

In Chapter 6, the wave height and velocity histories at S9 were described through video analysis. Since in the next section, the author want to use simulation wave height and velocity to evaluate the tsunami mechanisms on S9, a comparative analysis at $\mathrm{S9}$ between simulation result of Spot 3 and video result (Spot A, Fig.20) was conducted.

First, the simulation and video wave height histories are shown in Fig. 37. As discussed in Chapter 6 , the measurement in the video analysis of Spot A was conducted from $31.00 \mathrm{~min}$. to $42.82 \mathrm{~min}$. and the tsunami began to rise at about 36min. During that measurement time span, the maximum tsunami height did not materialize. To add the maximum height, the survey result of the Joint Survey Group ${ }^{13)}$ was checked and the maximum height of $16.2 \mathrm{~m}$ was obtained (T.T.+, average of five survey spots in Utatsu town). Besides, based on the video, the maximum height was confirmed to have occurred before $44 \mathrm{~min}$., since after this time, the tsunami began to recede. For simulation history, the wave height begins to run up at about $37 \mathrm{~min}$., and the maximum height of $18.8 \mathrm{~m}$ occurs at $43.33 \mathrm{~min}$. After 43.33min., the wave begins to fall back.

By comparison, it will be noted that the wave heights of the two analyses begin to rise at close time point and show similar variation trends. The difference between maximum heights is less than $14 \%$. Thus, it is proper to use simulation height to study the inundation process around the girder.

Second, the simulation and video wave velocities are plotted in Fig.38. For the video result, the tsunami velocities are measured twice as discussed in Chapter 6 and the maximum value obtained was $4.39 \mathrm{~m} / \mathrm{s}$. For the simulation, the tsunami velocity history from $37 \mathrm{~min}$. to $44 \mathrm{~min}$. was plotted. The tsunami velocity began to increase at $37 \mathrm{~min}$., and then reached maximum $4.06 \mathrm{~m} / \mathrm{s}$ at $41.92 \mathrm{mim}$.

By comparison, the results of the two analyses show similar variation trends. The difference between the maximum values of simulation and video results is less than $10 \%$, which is a small gap. Therefore, it is proper to use simulation velocity to evaluate the tsunami force on S9 by Eq. (2).

\section{(4) Outflow evaluation of S9}

After the description of the tsunami characteristics, in this section, the outflow evaluation of S9 is carried out once more using the simulation result of Spot 3.

Same to Fig.25 and Fig.26, the two mechanisms of

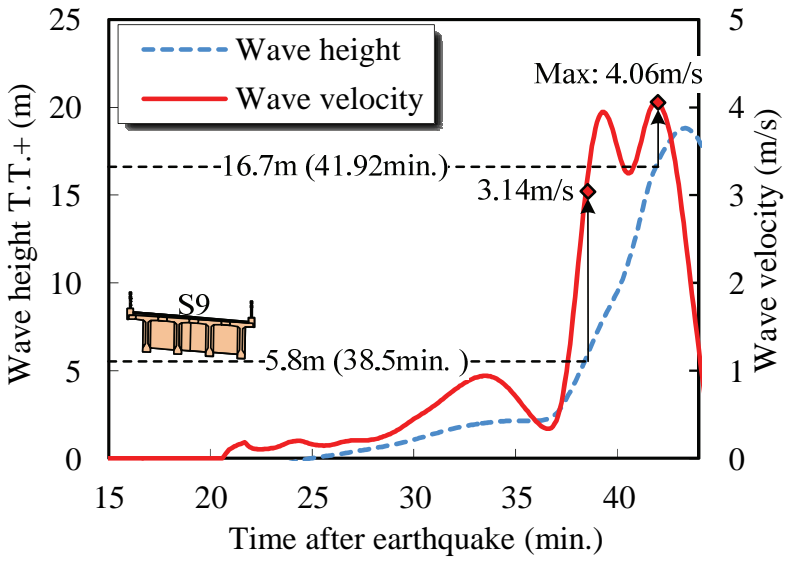

Fig.35 Wave height and velocity histories (Spot 3).

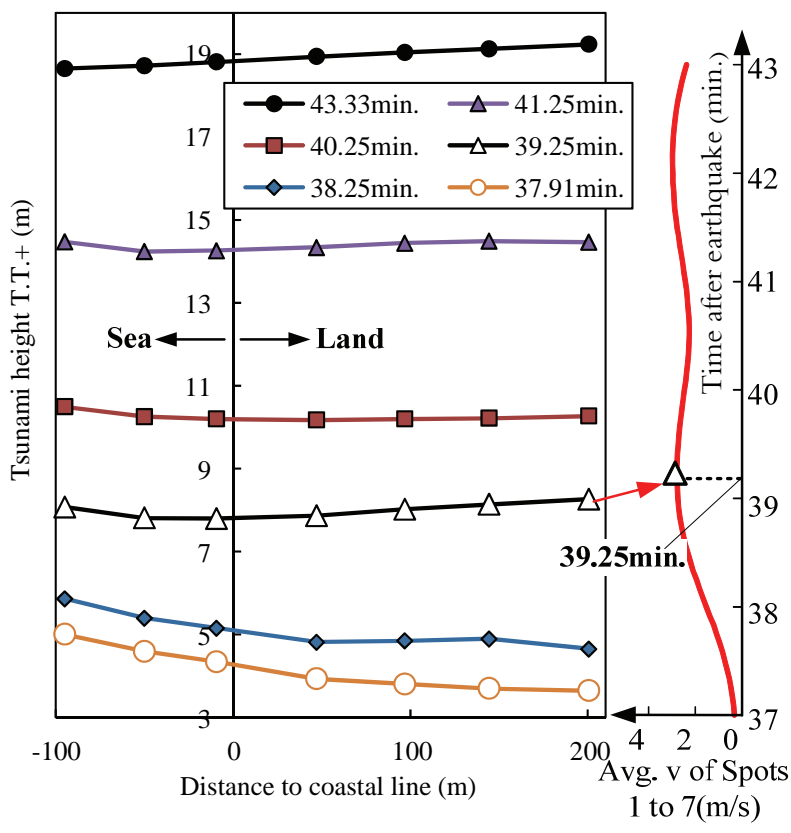

Fig.36 Characteristics of wave height distribution (Spots 1 7).

different inundation conditions for S9 are analyzed. As shown in Fig.20, Mechanism 1' happens at around $38.5 \mathrm{~min}$., when the tsunami height runs up to $5.8 \mathrm{~m}$ and begins to impact on S9; For Mechanism 2', the inundation condition at $41.92 \mathrm{~min}$., when the maximum wave velocity occurs, is selected. This time, S9 is submerged. Besides, it is known that the wave velocities corresponding to the two mechanisms are $3.14 \mathrm{~m} / \mathrm{s}$ and $4.06 \mathrm{~m} / \mathrm{s}$, respectively.

Next, using same method decribed in Chapter 6.3, the S9 is impacted horizontally by the tsunami force (Eq. (2)), and the friction resistance. For the computation of friction resistance, at 38.5min., when S9 is not submerged, buoyancy is ignored (Eq. (2)) while at $41.92 \mathrm{~min}$., when S9 is submerged totally, buoyancy should be considered (Eq. (3)). To compare friction resistance and tsunami force, their $\beta$ ratios $\left(\beta_{1}\right.$, and $\beta_{2}$, ) were calculated and are shown in Fig.39. The results show that similar to the video 
analysis (Fig.27), when S9 is submerged totally, $\beta$ has a value close to 1.0 , which means that S9 can easily be swept away.

\section{CONCLUSIONS}

Based on the $\beta$ ratio analysis, the video and nurmerical analyses on the tsunami progress at Shizugawa Town and Utatsu Bridge, the conclusions are summarized as follows:

(1) From the outflow evaluation of 37 bridge girders, when velocity $6.0 \mathrm{~m} / \mathrm{s}$ was applied, girders with $\beta$ greater than 1.5 suffered Rank C damage and girders with $\beta$ smaller than 0.6 suffered Rank A damage. Thus, it is possible to use $\beta$ to evaluate the outflow of girders.

(2) Based on the tsunami height variation at Hachiman Bridge of Shizugawa Town, two outflow mechanisms on the bridge girder at Shizugawa were analyzed. One type was that tsunami just acted on girder and did not submerge it (the buoyancy was ignored); the other type was that tsunami submerged girder totally (the buoyancy was considered). It was concluded that for both the two mechanisms, $\beta$ of Hachiman Bridge were 2.76 and 5.51, respectively. Therefore, the girder resistances of Hachiman Bridge were great enough to resist tsunami action.

(3) Based on the field survey of Utatsu Bridge, S3 S10 were displaced from their supports while S1 S2 and S11 S12 survived. From the wave velocity distribution at 38.50min. (Fig.33), it was noted that while Utatsu Bridge was affected by the tsunami, the wave velocity at the bridge middle part was relatively greater than the end parts, due to the blockage by the mountain and the water gate.

(4) The wave height and velocity time histories by video and simulation analyses showed similar trends and levels at S9 of Utatsu Bridge, which indicates that the numerical analysis at Utatsu Bridge is reasonable

(5) By video and simulation analyses, two types of outflow mechanisms on S9 were evaluated (the first type referred to the mechanism when the tsunami only hit S9 but did not submerged it; the second type refers to the mechanism when the tsunami submerged S9 and the maximum wave velocity occurred). The total submersion confirmed that the friction resistance of S9 was insufficient to resist the tsunami force, thus it was swept away.

\section{REFERENCES}

1) Japan Road Association: Specifications for Highway Bridges Part I Common, pp. 52-57, 2002.

2) Rabbat, B. G. and Russel, H. G.: Friction coefficient of steel on concrete or grout, Journal of Structural Engineering, ASCE, Vol. 111, No. 3, pp. 505-515, 1985.

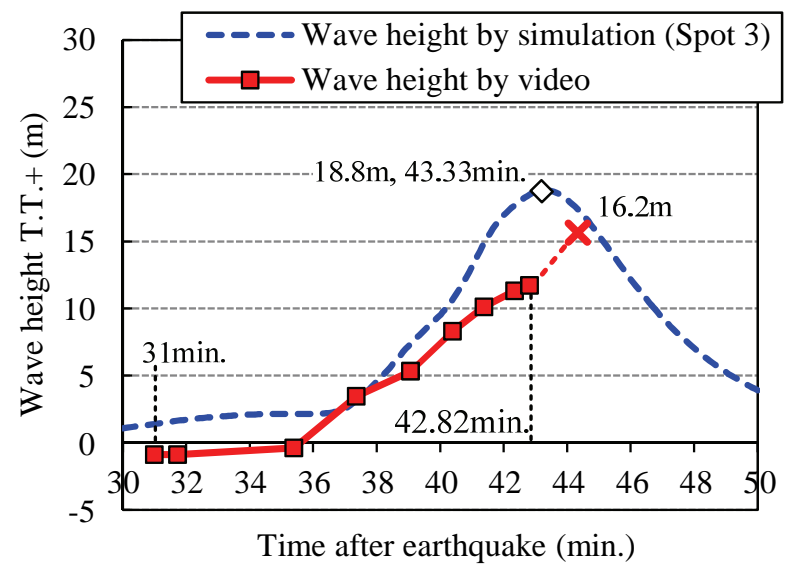

Fig.37 Comparison of wave height histories.

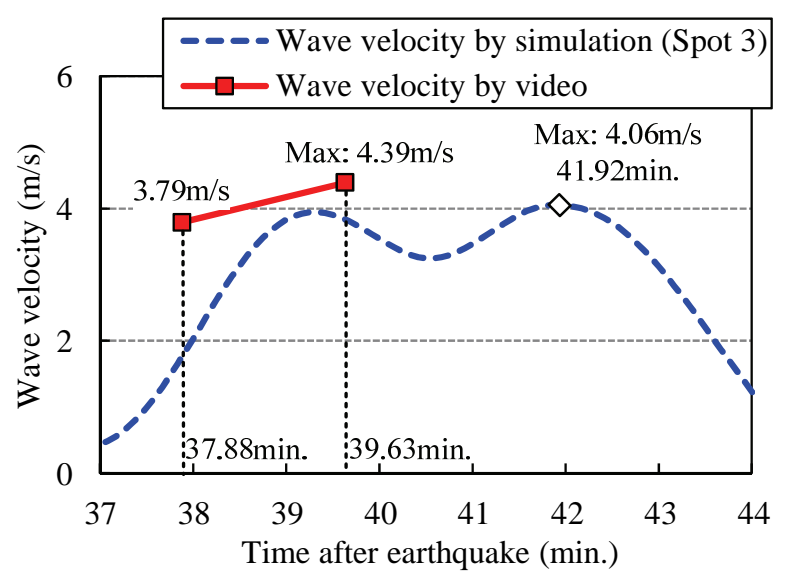

Fig.38 Comparison of wave velocity histories.

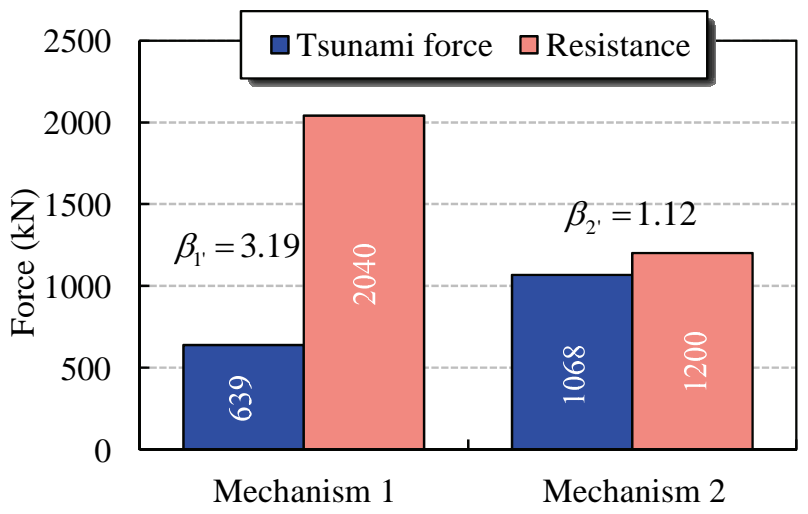

Fig.39 Outflow evaluation of S9 by simulation.

3) Fu, L., Kosa, K., Shimizu, H. and Zheng, Y.: Damage to Structures due to Tsunami and Evaluation of Tsunami Velocity in Shizugawa, Proc. of JCI, Vol. 34, pp. 805-810, 2012.

4) Kosa, K., Nii, S., Shoji, G. and Miyahara, K.: Analysis of Damaged Bridge by Tsunami due to Sumatra Earthquake, Journal of Structural Engineering, JSCE, Vol. 55A, pp. 454-463, 2010.

5) Zheng, Y., Kosa, K., Shimizu, H. and Fu, L.: Damage to Structures in Rikuzentakata Region Due to Tsunami, Proc. of JCI, Vol. 34, pp. 811-816, 2012.

6) Graduate School of Resource Sciences of Department of 
Civil and Environmental Engineering of Akita University: Survey of bridge structures of Miyagi Prefecture, Apr. 2011, (http://www.str.ce.akita-u.ac.jp/br/miyagi_str.html)

7) Komatsu, T. and Ogushi, K.: Newly Organized Hydraulics, Rikotosho, pp. 9-12, Apr. 2011.

8) Fujii, Y. and Satake, K.: Source Model of Seismic Wave of Tohoku Earthquake on 11th March of 2011, http://iisee.kenken.go.jp/staff/fujii/OffTohokuPacific2011/t sunami_ja.html.

9) Ministry of Land, Infrastructure and Transport, National Institute for Land and Infrastructure Management, Coast Division River Department, Simulation Guide of Heisei 23 Year for Tsunami due to Tohoku Earthquake, pp. 15, 2011.

10) Mansinha, L. and Smylie, D. E.: The Displacement Fields of
Inclined Faults, Bulletin of the Seismological Society of America, Vol. 61, No. 5, pp. 1433-1440, 1971.

11) Port and Airport Research Institute, Nationwide Ocean Wave Information Network for Ports and Harbours, Observed Data of Tohoku Earthquake, http://nowphas.mlit.go. $\mathrm{jp} /$.

12) Geospatial Information Authority of Japan, Inundation Area of 1/50 scale, http://www.gsi.go.jp/common/000061546. pdf.

13) The 2011 Tohoku Earthquake Tsunami Joint Survey Group, Survey of Tsunami Inundation and Runup, http://www. coastal.jp/ttjt/index.php.

(Received June 25, 2013) 